\title{
CULTURA, MODERNIDADE E DIREITO: DIFICULDADES, POSSIBILIDADES E DIÁLOGOS A PARTIR DE LUHMANN
}

\author{
CULTURE, MODERNITY AND LAW: DIFFICULTIES, POSSIBILITIES AND DIALOGUES BY
}

LUHMANN

Lucas Fucci Amato*

Resumo:

Os debates sobre relativismo e universalismo cultural, que informam as concepções de modernidade e do direito moderno (particularmente no campo dos direitos humanos), pressupõem um enquadramento sociológico sobre as condições de produção de sentido na sociedade mundial e no sistema jurídico. Este artigo pretende apresentar algumas reflexões sobre os desafios de se analisar a cultura na teoria dos sistemas desenvolvida por Niklas Luhmann, assim como avançar nas possibilidades de um diálogo jurídico intercultural, baseado nos pressupostos tanto da teoria dos sistemas quanto da "hermenêutica diatópica" proposta por Boaventura de Sousa Santos. Outras perspectivas, como as da "transculturalidade" (Wolfgang Welsch) e das "múltiplas modernidades" (Shmuel Eisenstadt), são incorporadas à discussão.

Palavras-chave: Teoria dos sistemas. Direito e cultura. Modernidade. Diálogo cultural.

\begin{abstract}
:
Debates on cultural relativism and universalism, which inform the conceptions of modernity and modern law (particularly in the field of human rights), presuppose a sociological framework concerning the conditions of sense-making production in the global society and in the legal systems. This paper intents to present some reflections about the challenges in the analysis of culture within the systems theory as developed by Niklas Luhmann, and to advance possibilities of a legal intercultural dialogue, based on the presuppositions of system theory as so as on the 'diatopic hermeneutics' proposed by Boaventura de Sousa Santos. Other perspectives, as that of 'transculturality' (Wolfgang Welsch) and of 'multiple modernities' (Shmuel Eisenstadt), are brought into discussion.
\end{abstract}

Keywords: Systems theory. Law and culture. Modernity. Cultural dialogue.

1. Introdução

O sistema jurídico vem sendo atualmente confrontado com a necessidade de processar internamente demandas culturais, de reconhecimento de diferenças e respeito

\footnotetext{
Doutorando em Filosofia e Teoria Geral do Direito pela Faculdade de Direito da Universidade de São Paulo. Contato: lucas.amato@usp.br.
} 
à diversidade das formas de vida. Nas ordens nacionais e internacionais, a cultura deixa de ser contraposta ao direito, para ser construída como um tipo de pretensão normativa: o direito à cultura, ou os direitos culturais. Nos planos mais abrangentes de reflexividade das respectivas ordens jurídicas, seja como direito fundamental garantido em constituições nacionais, seja como gênero dos direitos humanos internacionais, a cultura passa a ser uma diferença que faz a diferença nos juízos jurídicos.

Pode-se entender que uma adequada reflexão sobre cultura integra 0 âmbito de muitas normas de direitos humanos e fundamentais invocadas em conflitos jurídicos. Para Müller, ${ }^{1}$ o programa da norma, teor literal formulado no texto da norma, precisa ser coordenado ao âmbito da norma, que compreende a realidade normada, não só enquanto referência material juridificada, mas também codificada por outros sistemas: há, notadamente no campo constitucional e especialmente no que concerne aos direitos humanos e fundamentais, "âmbitos de normas mais complexos e integral ou parcialmente não-gerados pelo direito [...]". ${ }^{2}$ Isso significa que a concretização normativa não pode prescindir da (auto)delimitação textual pelo programa da norma, mas necessita considerar o próprio âmbito da norma como realidade selecionada pelo programa da norma. São ambos, ao lado do âmbito do caso, fatores codeterminantes das decisões jurídicas.

A formulação de questões culturais como problemas de direito incita à redefinição de categorias tradicionais, como a de direito subjetivo - afinal, os direitos culturais afirmam-se contrafaticamente tanto no plano individual quanto no de coletividades; o próprio pluralismo jurídico, antropologicamente diagnosticado, passa a ser reconhecido pelas ordens jurídicas positivas estatais, já que o foro étnico e as concepções substanciais de direito de cada cultura autóctone ou minoritária integram a própria cultura cujo reconhecimento é demandado como direito.

As questões elencadas sugerem elaborações e propostas distintas segundo as diversas perspectivas de fundamentação do debate: universalismo versus relativismo cultural, prevalência da constituição sobre os costumes indígenas, conflitos étnicos, garantias democráticas às minorias. Explora-se aqui a perspectiva que a teoria dos sistemas sociais de Niklas Luhmann pode oferecer a esse debate. As dificuldades e possibilidades trazidas por uma leitura das questões culturais sob tal ótica são acentuadas e exigem um diálogo com outras formulações conceituais. Particularmente, é evidenciado aqui um paralelismo possível da teoria dos sistemas com a proposta de Boaventura Santos centrada

\footnotetext{
1 MÜLLER, Friedrich. Métodos de trabalho do direito constitucional. Tradução de Peter Naumann. 3. ed. Rio de Janeiro: Renovar, 2005. p. 38-47; Teoria estruturante do direito I. Tradução de Peter Naumann e Eurides Avance de Souza. 2. ed. São Paulo: Revista dos Tribunais, 2009. p. 244-268.

2 MÜLLER, Friedrich. Métodos de trabalho do direito constitucional. cit., p. 29.
} 
na "hermenêutica diatópica" como condição para uma concepção "multicultural" de direitos humanos.

\section{Cultura, comunidade e diferenciação funcional}

\section{A Organização das Nações Unidas para Ciência, Educação e Cultura} (UNESCO), após um debate de escritores, críticos, cientistas e investigadores da cultura, chegou à conclusão de que a cultura "representa para nós o conjunto dos meios criados pelo homem para assegurar a sua existência. A cultura é um meio de comunicação entre os homens; é a própria essência do ser humano". ${ }^{3}$ Quase quatro décadas depois, a organização considerou que “"[c]onteúdo cultural' refere-se ao caráter simbólico, dimensão artística e valores culturais que têm por origem ou expressam identidades culturais". ${ }^{4}$ Muito ilustrativa é a retrospectiva da visão de cultura adotada pela UNESCO ao longo das décadas:

Tendo sido por muito tempo vista pelo ângulo das belas artes e da literatura, a cultura abrange um campo muito mais amplo: 'a cultura deve ser considerada como um conjunto distinto de elementos espirituais, materiais, intelectuais e emocionais de uma sociedade ou de um grupo social. Além da arte e da literatura, ela abarca também os estilos de vida, modos de convivência, sistemas de valores, tradições e crenças' (Preâmbulo da Declaração Universal de Diversidade Cultural da UNESCO, 2001).

Em retrospectiva, é possível identificar quatro etapas principais na transformação do sentido e das funções atribuídas à cultura. Naturalmente, essas etapas não são rigorosamente separadas; do mesmo modo, as atividades conduzidas em cada uma delas prosseguiram durante as etapas seguintes:

(i) A ampliação do conceito de cultura como produção de arte, de modo a incluir a noção de identidade cultural (anos 50 e 60). Durante esse período, a UNESCO buscou defender culturas em resposta a situações específicas, tais como os contextos de descolonização, ao reconhecer a igual dignidade das culturas;

(ii) A construção da consciência de vínculo entre cultura e desenvolvimento como fundamento da cooperação

3 Preâmbulo da Declaração sobre os Direitos Culturais como Direitos do Homem, de 1968. Cf. UNESCO. Os direitos culturais como direitos do homem. Porto: Telos, 1973.

4 Art. 4.2, da Convenção da UNESCO sobre a Proteção e Promoção da Diversidade das Expressões Culturais, de 2005 . 
internacional e da solidariedade para com os países em desenvolvimento (anos 70 e 80). Durante esse período e juntamente com as atividades anteriormente iniciadas, a UNESCO passou a enfatizar o intercâmbio recíproco dos países e das sociedades, de modo a tornar possível o estabelecimento de parcerias em igualdade entre os mesmos;

(iii) $\mathrm{O}$ reconhecimento das aspirações e bases culturais na construção das democracias (anos 80 e 90). Durante esse período, a Organização demonstrou ciência das várias formas de discriminação e exclusão vividas por pessoas que pertencem a minorias, povos indígenas e populações imigrantes;

(iv) O aprimoramento do diálogo entre culturas e civilizações em sua rica diversidade, considerada como patrimônio comum da humanidade pela UNESCO em sua Declaração Universal da Diversidade Cultural (anos 90 e 2000). Em consonância com a definição mais ampla de cultura, a Declaração lida com o duplo desafio da diversidade cultural: por um lado, ao assegurar a interação harmônica entre pessoas e grupos com identidades culturais plurais, variadas e dinâmicas, bem como o desejo da vida em conjunto; e, por outro, ao defender a diversidade criadora, ou seja, a grande variedade de formas pelas quais as culturas revelam as suas próprias expressões tradicionais e contemporâneas no espaço e no tempo. Durante esse período, a UNESCO buscou atender às necessidades das sociedades cujo caráter plural foi ampliado pelo acelerado processo de globalização.

Por ser um processo contínuo, flexível e mutável, a cultura remodela o seu próprio patrimônio material e imaterial, enquanto novas formas de expressão são geradas, revelando, assim, a sua infinita diversidade. Em meio a um ambiente internacional em constante mudança, a UNESCO sempre buscou trazer soluções práticas para os desafios específicos apresentados por cada momento histórico. Com sua capacidade de promover o diálogo e a criatividade, a diversidade cultural se mostra como condição essencial para a paz e para o desenvolvimento sustentável. ${ }^{5}$

A noção de cultura, crescentemente vaga e de fluída historicidade, tem por referência original o âmbito material e concreto da existência social, passando depois a

UNESCO (Organização das Nações Unidas para Ciência, Educação e Cultura). Dez chaves para entender a Convenção para a Proteção e a Promoção da Diversidade das Expressões Culturais adotada pela $33^{\mathrm{a}}$ Sessão da Conferência Geral da UNESCO em 2005. Brasília: UNESCO, 2007. Disponível em: <http://www. unesco.org/new/pt/brasilia/culture/international-instruments-clt/\#c154809>. Acesso em: 15 jan. 2012. p. $20-21$. 
designar metaforicamente o plano ideal e simbólico da produção e reprodução da vida humana. Designa tanto infraestrutura quanto superestrutura, semântica e estrutura, o que há de mais concreto (formas de organização social) e de mais abstrato (a arte, a linguagem), tendo por núcleo de sentido comum a referência ao que é criado pelo trabalho e também pode ser destruído criativamente. ${ }^{6}$ Em definições um tanto quanto imprecisas, ora por "cultura" se faz referência a (quase) toda a sociedade, ${ }^{7}$ ora se reforça a proeminência do sistema educacional em nesse âmbito, ${ }^{8}$ o que destaca a "exigência de que os indivíduos devem 'apropriar-se' da cultura de maneira individualmente adequada (formação)". 9

Poder-se-ia entender "simbólico" na contraposição com "concreto". Muitas vezes, a cultura é concebida enquanto abarcando o "simbólico"; noutras tantas, vem definida como totalidade do concreto e do simbólico - algo igual ou maior que a própria sociedade ou a própria vida. Mas como pensar tais distinções dentro do paradigma luhmanniano para qual toda operação no interior da sociedade é comunicação e o conceito de observação abarca também a ação?

Mesmo se apartada do campo especificamente educacional (formação profissional), a cultura mantém uma ambiguidade intrinsecamente marcada pelo distanciamento entre quem produz a semântica da sociedade e quem trabalha sua estrutura material: a referência ora à cultura em um sentido amplo (antropológico) - as formas de

6 EAGLETON, Terry. A idéia de cultura. Tradução de Sandra Castello Branco. São Paulo: Ed. Unesp, 2005. p. 10-13.

7 Já Parsons, mentor intelectual de Luhmann, tinha em mente a discordância que reinava nas ciências humanas sobre a definição de cultura, alguns a identificando à própria sociedade, outros considerando-a derivada da sociedade, outros até mesmo compreendendo a sociedade (sistema social) como parte da cultura. Cf. MARCARIAN, Eduardo S. Lugar e papel das investigações da cultura nas ciências sociais modernas. In: ENGELS, Friedrich; GEERTZ, Clifford; BAUMAN, Zygmunt; LEONTIEV, Alexei; MARCARIAN, Eduardo. O papel da cultura nas ciencias sociais. Porto Alegre: Villa Martha, 1980. p. 97103. Para Vilanova: "A cultura é uma intersecção de três linhas, um domínio da objetividade includente do puramente natural, das formas de interação e das significações que os homens incorporam em suas condutas recíprocas e nas coisas que, por isso mesmo que são mediadoras dos significados, são coisas símbolos. A separação é, sabe-se, tão somente abstrata, por ordem de discernimento conceptual. Na realidade, as três dimensões estão sempre juntas e nenhuma desfruta a primazia de funcionar como variável livre. A interconexão é a regra, por isso que necessário se faz evitar o reducionismo, assim como o causalismo unilateral. O reducionismo qualquer que seja: o naturalismo, o sociologismo, ou o culturalismo (idealista). E o unilateralismo causal, tomando o fator natural (geográfico, biológico), ou o mecanismo das relações recíprocas, ou as ideias (valores, significação, concepções espirituais: jurídicas, éticas, filosóficas), como determinantes independentes de toda estrutura e de toda dinâmica histórico-social". VILANOVA, Lourival. Notas para um ensaio sobre a cultura. In: Escritos jurídicos e filosóficos. São Paulo: Axis Mundi; Ibet, 2003. p. 280.

8 Para Bosi: "Cultura é o conjunto das práticas, das técnicas, dos símbolos e dos valores que se devem transmitir às novas gerações para garantir a reprodução de um estado de coexistência social. A educação é o momento institucional marcado do processo". BOSI, Alfredo. Colônia, culto e cultura. In:

Dialética da colonização. São Paulo: Companhia das Letras, 1992. p. 16.

9 LUHMANN, Niklas. La sociedad de la sociedad. Tradução de Javier Torres Nafarrate. México: Herder, 2007. p. 698. 
ser, produzir e viver, os valores e práticas cotidianos (associados ao povo “comum”), ora à arte, como nível simbólico complexo, intencionalmente criado para a contemplação, segundo cânones formais e técnicas profissionais, um campo de autorreflexão da própria cultura em sentido antropológico - a arte erudita, clássica, de elite. ${ }^{10}$

A dicotomia entre natureza e cultura é um ponto de partida, mas simplesmente identifica cultura a sociedade, que passam a apresentar-se com idênticos limites: os limites da comunicação, operacionalizada pela linguagem, que resulta do acoplamento de cada consciência individual à sociedade (sistema mais abrangente que existe, cujas unidades sejam comunicações). A cultura, como toda produção humana, como tudo o que comunica é, assim, definida em muitas descrições como o centro constitutivo do sentido de "ser humano". Para a sociedade, a natureza não é mais do que um referente que pauta comunicações - só assim, a natureza, no ambiente da sociedade, reentra a sociedade. Pode-se pensar na hipótese de que, historicamente, partiu-se de conceitos de cultura como tudo o que não é natureza. A distinção natureza/cultura guiava então a hetero-observação da sociedade, sociedade esta, com dimensões exatamente iguais às da cultura; sociedade como não-natureza. Progressivamente, porém, o conceito de cultura sofreu grandes transformações, tendo como causa e efeito sua posição de destaque nas comunicações travadas nas várias épocas no interior da sociedade, na construção de sentidos basilares sobre a própria sociedade (auto-observação). Assim é que as autodescrições da sociedade segundo as formas segmentárias, hierárquicas, central-periféricas e funcionais levaram a análogas conceituações de cultura, por dicotomias tais como cultura nacional/cultura estrangeira (forma segmentária) e cultura de elite/cultura popular (forma hierárquica). Essas dicotomias todas, porém, foram assim expressadas relevantemente apenas na sociedade moderna, na qual coexistem os diversos princípios de diferenciação, com uma predominância do princípio funcional na atualidade, segundo Luhmann. ${ }^{11}$ Isso porque o conceito de cultura (pensado como "essência humana", assim como a razão) designou, em muitos tempos e espaços, apenas os "mais humanos" - isto é, os mais bem posicionados em sociedades cuja divisão interna era estratificada. Como o conceito de sociedade como sociedade mundial apenas se faz verossímil à medida que a operação elementar da sociedade - a comunicação - difunde-se com menor limitação de barreiras espaciais, ${ }^{12}$ o conceito de sociedade permaneceu restrito a circunscrições territoriais limitadas - até o século XX, sociedade se identificava com país, com o território delimitado pelo Estado representativo da respectiva nação. Nas relações entre as sociedades (países), a predominância da diferenciação segmentária (a própria divisão em países ou em Novo e Velho Mundo) não

\footnotetext{
10 EAGLETON, Terry. A idéia de cultura. cit., p. 167.

11 LUHMANN, Niklas. La sociedad de la sociedad. cit., p. 502-615.

12 Id., esp. p. 108-129.
} 
excluía a importância dos princípios hierárquicos e da forma centro-periferia (esta última ainda presente, segundo muitas autodescrições da sociedade contemporânea). ${ }^{13}$ A cultura, então, foi entendida como atributo de todos os seres humanos, com grandes diferenças de grau, ou mesmo como propriedade inerente apenas a alguns - aqueles posicionados nas melhores camadas, classes ou estamentos e/ou nas sociedades (países) centrais, superiores (caso da visão da cultura como atributo só europeu). Notadamente a partir do século XIX e durante a maior parte do século XX, os discursos sobre cultura buscaram afirmá-la como característica de todo ser humano e, por dicotomias como "cultura erudita/cultura popular", expressaram a ideia de que seu conteúdo seria determinado pela luta de classes resultado do capitalismo. De uma concepção estrita e elitista (só têm cultura a Europa e/ou certos homens) a uma concepção dicotômica (todos têm cultura, mas esta se cinde como as classes sociais), a cultura passou finalmente a uma concepção pluralista, visualizável nos diversos discursos que tratam do multiculturalismo. As identidades constituídas não-só por uma situação de classe (econômica), mas principalmente por referências de gênero, de etnia, de religião e tantas outras. Essa passagem corresponde, em termos quase caricaturais, à transição de autodescrições "marxistas" sociais focadas na economia (nas quais economia e política eram vistas como os sistemas centrais da sociedade - ou um só sistema central) para autodescrições "pós-modernas" focadas na cultura e na identidade, termos pouco discerníveis já que o paradigma é da "fragmentação" e globalização do sujeito, do mundo, da economia, das experiências de sentir e pensar.

Um conceito de cultura adequado só pode ser um autoconceito de cada comunidade cultural, embora uma visão da teoria sistêmica possa partir da semântica da diferenciação funcional para traduzir esse autoconceito em termos sociológicos, sem deixar de abrir-se cognitivamente às autorrepresentações das respectivas comunidades. ${ }^{14}$ As comunidades culturais têm diferentes níveis de abertura ao seu exterior (às outras comunidades) - poder-se-ia entender que algumas comunidades se comportam analogamente a organizações, como sistemas autopoiéticos no interior da sociedade mundial possíveis mesmo fora de um sistema funcional. ${ }^{15}$

Luhmann observa "a história da sociedade como a história geral da evolução sociocultural" $"$ e considera a cultura como "elevada esfera da realidade em que todos os

13 Id., p. 17, 119, 451, 485, 563, 927, 946, comentando sobre Wallerstein.

14 Em sentido semelhante, Teubner e Fischer-Lescano apontam para a "colisão de formas de diferenciação social" e defendem, como solução possível, embora não ideal, a reconstrução da cultura "tradicional" pelo direito "moderno", com uma abertura deste àquela. TEUBNER, Gunther; FISCHER-LESCANO, Andreas. Cannibalizing epistemes: will modern law protect traditional cultural expressions? In: GRABER, Christoph; BURRI-NENOVA, Mira (Eds.). Intellectual property and traditional cultural expressions in a digital environment. Cheltenham: Edward Elgar, 2008. p. 27-34.

15 Cf. LUHMANN, Niklas. La sociedad de la sociedad. cit., p. 655-672.

16 LUHMANN, Niklas. El arte de la sociedad. Tradução de Javier Torres Nafarrate. México: Herder, 2005. p. 
testemunhos da atividade humana se registram pela segunda vez - não sob o aspecto de sua utilidade, senão sob sua comparação com outros testemunhos culturais". ${ }^{17}$ Nota que a cultura, como plano mais abstrato de reflexão, auto-observação e autodescrição da sociedade, reforça diferenciações - segmentárias, distinguindo culturas nacionais; estratificadas, distinguindo a cultura da elite da cultura do povo ou popular; centro/ periferia, distinguindo os centros produtores da cultura mais valorizada e seus meros receptores; funcionais, expressando a quebra de uma orientação de sentido uniforme em uma sociedade especializada. Dessa forma, produz representações de mundo e aloca as identidades de cada unidade que designa. Há uma objetividade aparente das descrições culturais, pois a relatividade de seu objeto implica a necessidade de "comparação de culturas e relativismo histórico". ${ }^{18}$ Assim: "Desde finais do século XVIII o conceito de cultura ocupa o lugar no qual as autodescrições se refletem. Cultura, no sentido moderno, sempre é a cultura refletida como cultura, i.e., uma descrição observada no sistema" ${ }^{19}$

A difícil definição do conceito de cultura ${ }^{20}$ leva à necessidade de delimitá-lo - ainda que apenas heuristicamente - de forma operacionalmente frutífera. Partindo-se do arcabouço teórico da teoria dos sistemas luhmanniana, que visualiza um sistema artístico autopoiético, mas não um sistema cultural, busca-se dar sentido, dentro dessa semântica científico-social, ao conceito de cultura - historicamente obscuro e dinamicamente mutante nos últimos séculos, reavivado pelas análises sociológicas a partir dos anos 90 , que trocaram a tradicional ênfase no sistema econômico por abordagens "culturalistas". $\mathrm{Na}$ tradição filosófica ocidental, a cultura é uma condição para a política - "ser homens primeiro e cidadãos depois" 21 -, confundindo-se com a formação técnica e o desenvolvimento ético e estético da pessoa. A moral, a educação e arte necessitam, pois, de uma conformação política para a construção da boa vida na pólis.

Na sociedade moderna, entretanto, as esferas da vida social se diferenciam. Neste trabalho, a partir de Luhmann, mas não estritamente com base em seu construto teórico, adota-se um duplo uso do termo cultura. De um lado, trata-se de um âmbito

354.

17 Id., p. 349.

18 LUHMANN, Niklas. La sociedad de la sociedad. cit., p. 698-699.

19 Id., p. 698 (grifo no original).

20 Ao analisar a cultura como um dos conceitos centrais das ciências humanas, Abraham Moles (1975: 10) afirma: "Assim, poderíamos dogmaticamente rejeitar a pesquisa de uma definição de uma palavra tão geral como 'cultura' [...]. [...] Sem chegar a tal ponto, o que seria esvaziar de seu sentido a própria operação de definição, ater-nos-emos à idéia de uma definição aberta, sempre acessível a retoques e adições, e opostas às definições fechadas às quais nos habitua a Geometria. Uma das grandes contribuições das ciências humanas às ciências exatas foi, com efeito, a dos 'fenômenos imprecisos' que é possível limitar, mas não definir, desvanecendo-se o fenômeno em sua própria definição". MOLES, Abraham A. Sociodinâmica da cultura. Tradução de Mauro W. Barbosa de Almeida. São Paulo: Perspectiva; Edusp, 1975. p. 10.

21 EAGLETON, Terry. A idéia de cultura. cit., p. 17. 
comunicacional "trans-sistêmico" da sociedade mundial que abarca os sistemas funcionais da educação, da ciência, da arte, da religião e dos meios de comunicação e sistemas organizacionais e de interação não necessariamente subsumidos a esses sistemas funcionais (ou a qualquer outro). De outro lado, cultura é referida como comunidade cultural (de diferentes proporções), referência geralmente espacial (mais estreita ou mais ampla, no limite global) a que se vinculam as comunicações, referência esta implícita ou explícita, muitas vezes pressuposta; o âmbito espacial de uso difundido de certas ideias (expressas linguística ou artisticamente nas comunicações) e seus respectivos pressupostos cognitivos. Certas ideias - e consequentemente as comunicações que as veiculam - têm comunicabilidade mais restrita (vinculando-se a pessoas de uma comunidade menor), outras têm comunicabilidade mais amplas, sendo eficazes no espaço global, para a grande maioria das pessoas. Nessa perspectiva, comunidade não significa necessariamente integração, solidariedade e consenso - distanciando-se, pois, da teoria parsoniana ${ }^{22}$-, mas simplesmente um locus, de fronteiras móveis e difusas, tão variáveis quanto as pessoas que se socialibizaram nesse locus, em que vige genericamente um uso frequente de certas ideias - traduzidas em comunicações - e suas respectivas expressões simbólicas. Também não há uma identificação precisa e imediata de comunidades culturais a países, (sub) continentes, regiões subnacionais ou quaisquer outras segmentações do espaço mundial, bem como não necessariamente há uniformidade cultural entre pessoas que compartilhem um mesmo grau de "inclusão" econômica, cultural, etc., ao redor do mundo. Podemos entender comunidade não no sentido antigo de tradição e consenso, mas em um sentido reformulado, de "zona de aumento da vulnerabilidade mútua, dentro da qual as pessoas ganham uma oportunidade de resolver mais completamente o conflito entre as condições capacitadoras da autoafirmação: entre sua necessidade de ligação e de participação na vida de grupo e o medo de subjugação e despersonalização com que esse engajamento pode ameaçá-las". ${ }^{23}$

Para Welsch, ${ }^{24}$ o conceito de cultura tradicionalmente compunha-se de três elementos: homogeneização social, consolidação étnica e delimitação intercultural (definição de uma cultura por contraste com as outras). A sociedade moderna, porém, não é capaz de operar, na amplitude espacial que constitui muitas de suas relações, em condições de homogeneidade cultural. Em qualquer espaço que se observe, por mais limitado que seja, podem, no mínimo, ser apontadas diferenças culturais "verticais" (a

22 PARSONS, Talcott. Sociedades: perspectivas evolutivas e comparativas. Tradução de Dante Moreira Leite. São Paulo: Pioneira, 1969. esp. p. 16-53.

23 UNGER, Roberto Mangabeira. Política: os textos centrais: a teoria contra o destino. São Paulo: Boitempo; Chapecó: Argos, 2001. p. 390.

24 WELSCH, Wolfgang. Transculturality: the puzzling form of cultures today. In: FEATHERSTONE, Mike; LASH, Scott (Eds.). Spaces of culture: city, nation, world. London: Sage, 1999. p. 194-195. 
partir de diferentes posições econômicas ou situações de classe) e "horizontais" (relativas a gênero, sexualidade, etc.). ${ }^{25}$ Quanto à consolidação étnica, a evidência histórica de uma contínua miscigenação na formação das populações ultrapassa a construção semântica de "culturas como esferas fechadas ou ilhas autônomas", territorial e linguisticamente baseadas e delimitadas.

A atenção ao multiculturalismo e conceitos afins, embora presente em seus equivalentes em certas semânticas nacionais, principalmente de países colonizados e de imigração (como o Brasil), apenas tomou status de um discurso científico de relevância global quando passou a ser pertinente à realidade dos países centrais, que ao fim do século XX tornaram-se também loci não mais de emigração, mas destacadamente epicentros de imigração - esse "ineditismo" explica a força quantitativa e qualitativa das teorias sobre o multi, pluri, trans ou interculturalismo e das referências a "desterritorializados" e a "populações de diáspora" ${ }^{26}$ na Europa, ${ }^{27}$ em particular. Por outro lado, nos Estados Unidos, onde houve na história moderna recente colonização e imigração, também se desenvolvem esses temas, decerto com base nos problemas raciais que o país historicamente vivenciou e que se reforçariam, em novas formas, pelas ondas de imigração de latino-americanos para lá dirigidas.

Welsch ${ }^{28}$ oferece uma distinção entre interculturalidade, multiculturalidade e transculturalidade. A interculturalidade busca opor à "estrutural inabilidade de comunicação entre culturas" e ao caráter conflituoso das relações interculturais a exigência de entendimento e tolerância. Enquanto a interculturalidade analisa o nível das relações entre sociedades nacionais, a multiculturalidade foca o interior dessas sociedades, visualizando na constituição multicultural de cada país, mais uma vez, oportunidades para o entendimento e a mútua compreensão e colaboração. O Autor critica ambos os conceitos por pressuporem a ideia tradicional de cultura como esfera social delimitada em termos de cada país (semântica nacional do século XIX), o que poderia levar a tendências de "separação e guetização". ${ }^{29}$ Propõe, então, o conceito de transculturalidade, como semântica de transição que aponta para a interpenetração de culturas e a formação de uma transculturalidade no lugar de múltiplas culturas. Dado o intercruzamento e a polinização

\footnotetext{
$25 \quad$ Id., p. 195.

26 TAMBIAH, Stanley J. Transnational movements, diaspora, and multiple modernities. In: EISENSTADT, Shmuel N. (Ed.). Multiple modernities. New Brumswick: Transaction, 2000. p. 163.

27 Cf. entre outros, SARTORI, Giovanni. Pluralismo, multiculturalismo e estranei: saggio sulla società multietnica. Milano: Saggi, 2007; AÑON, María José. El reconocimiento de los derechos culturales de las minorías en Europa. In: INSTITUTO E DERECHOS HUMANOS "BARTOLOMÉ DE LAS CASAS" UNIVERSIDAD CARLOS III DE MADRID; FUNDACIÓN EL MONTE. El derecho en red: estudios en homenaje al profesor Mario G. Losano. Madrid: Dykinson, 2006. p. 39-67.

28 WELSCH, Wolfgang. Transculturality: the puzzling form of cultures today. cit.

29 Id., p. 197.
} 
cruzada entre as culturas, cada uma constituindo sua "rede externa" de relacionamentos, emergem temas comuns (como os direitos humanos), abarcados por uma cultura global híbrida. Essa cultura "transcultural", "híbrida", constituiria atualmente as identidades individuais.

Há no discurso pretensamente descritivo de Welsch alguns problemas, além daquele compartilhado por muitos autores, relacionado a um sentimento de novidade quanto à ideia de que todas as culturas são híbridas, o que obviamente obedece a diferenças de grau e tempo (quando sofreram maior hibridização) e já constitui um senso comum para boa parte dos países periféricos, colonizados pelos Estados europeus, então autoconcebidos como portadores exclusivos da cultura, um conjunto homogêneo legado a este "povo" por sua tradição de excelência e humanismo.

Ao lado dessa crítica, válida para diversos dos autores que tratam do tema do multiculturalismo ou de assuntos correlatos, há outras que concernem ao texto de Welsch. Primeiro, não é totalmente verdade que os vínculos locais tenham perdido sentido na constituição das identidades individuais, muito menos que os graus atuais de mistura entre cultura local e cultura global sejam desejáveis, na perspectiva das pessoas que vivem tal intercruzamento cultural, nas diferentes quantidades de local e global que se adicionam à fórmula da sua cultura cotidiana. Por isso, é temeroso afirmar que o discurso sobre culturas regionais é meramente retórico e que hoje tudo é "transculturalmente determinado". ${ }^{30}$

Ainda, a disparidade de "contribuição" (forçada?) das diversas fontes de identidade (meios de comunicação de massa globais, folclore nacional, tradições locais, etc.) para constituição de uma cultura comum "transcultural" (formada pelas várias culturas e que, sinergicamente, vai além destas) não pode ser elidida pelo topos da rede, que no máximo pode servir como exigência normativa, não concretizada, de um diálogo intercultural em condições isonômicas de comunicabilidade entre culturas. Negando a figura do mosaico de culturas e defendendo que há uma constituição (avançada, mas ainda em curso) de uma "rede transcultural", Welsch ${ }^{31}$ parece menosprezar as assimetrias da comunicabilidade de cada cultura, autoconcebida como tal e assim reconhecida pelas outras, na conformação de uma cultura global. De certa forma, "aquilo a que chamamos globalização é sempre a globalização bem-sucedida de determinado localismo. Em outras palavras, não existe condição global para a qual não consigamos encontrar uma raiz local, uma imersão cultural específica", 32

$30 \quad$ Id., p. 198.

31 Id., p. 203.

32 SANTOS, Boaventura de Sousa. Por uma concepção multicultural de direitos humanos. In: (Org.). Reconhecer para libertar: os caminhos do cosmopolitismo multicultural. Rio de Janeiro: Civilização Brasileira, 2003.p. 433; Towards a multicultural conception of human rights. In: FEATHERSTONE, Mike; LASH, Scott (Eds.). Spaces of culture: city, nation, world. London: Sage, 1999. p. 216. 
Ao postular uma única cultura global, Welsch adota uma postura autodestrutiva deste conceito (cultura), que necessariamente implica comparação e relatividade, ${ }^{33}$ além de acabar enfatizando certas comunicações, "globais" - mais fortes, comunicáveis e difundidas por uma forte infraestrutura econômica e de comunicação de massa -, em detrimento de expressões de (sub)culturas de fato sobreviventes em meio ao senso comum global. A distinção entre inter, multi e transculturalismo não deve ser presidida, portanto, por uma rigidez que faça os conceitos serem manifestamente simplificados em relação a uma realidade complexa, que precisa ser estruturada em níveis de complexidade adequados quando de sua (auto)descrição. Nesse sentido, Boaventura Santos $^{34}$ propõe a superação do debate "intrinsecamente falso" entre "universalismo e relativismo cultural", pela inafastabilidade da noção de que "[t]odas as culturas são relativas".

\subsection{O sistema artístico}

Em parte, a cultura apresenta-se com observação de segunda ordem da arte, como observação da observação dos observadores (produtores e/ou contempladores) da arte. ${ }^{35}$ Por outro lado, a arte é uma condensação da cultura, fortificando as referências de sentido produzidas e compartilhadas em um (in)certo espaço, por um (in)determinado grupo. Isso porque a arte constitui identidades estáveis e entendimentos generalizados. ${ }^{36}$ Assim, a cultura, enquanto arte, toma a forma de autorreflexão da cultura, enquanto produção social do mundo - é a arte, em um plano simbólico, de elevada abstração, uma forma condensada de cultura, uma imagem da sociedade para si mesma.

No acoplamento estrutural entre sistema social (sociedade, sistema de comunicação) e sistema psíquico (sistema de consciência, que percebe), arte e linguagem

33 "Esse conceito reúne, desde seu surgimento, no final do século XVIII, componentes reflexivos e comparativos. A cultura sabe e diz por si mesma até os mínimos detalhes que é cultura. Ela constrói suas próprias distinções, históricas ou nacionalmente comparativas - primeiramente com gestos de superioridade da própria cultura em comparação com outras; hoje, com concessões abertas ou indiferentes a uma variedade de culturas. Mesmo se há e exatamente se há essa multiplicidade, pode-se, da mesma forma, permanecer com a própria cultura. A opção da moda por cultural diversity legitima ao mesmo tempo uma atitude básica conservadora em relação à própria cultura e uma relação apenas turística com as demais." LUHMANN, Niklas. A realidade dos meios de comunicação. Tradução de Ciro Marcondes Filho. São Paulo: Paulus, 2005. p. 143 (grifos no original).

34 SANTOS, Boaventura de Sousa. Por uma concepção multicultural de direitos humanos. cit., p. 441; Towards a multicultural conception of human rights. cit., p. 220-221.

35 LUHMANN, Niklas. El arte de la sociedad. cit., p. 349.

36 Id., p. 326 e 328: "A arte consolida as identidades mais adiante do que a natureza oferece por si mesma; e isso o faz com certa indiferença acerca das situações, dos contextos, dos materiais. Logra a condensação e, ao mesmo tempo, a confirmação da forma: confirma assim a ordem oculta do mundo. Na forma de falar dos gregos: corrobora as idéias ao mirar o essencial. [...] A amplificação se avalia como positiva porque comprova as generalizações e porque fixa as generalizações exitosas como 'lugares comuns"”. 
são equivalentes, marcando-se as diferenças porque "[a] arte se desempenha como comunicação mesmo que (e precisamente porque) não pode ser explicada adequadamente por meio de palavras e muito menos de conceitos"; $;{ }^{37}$ a arte comunica sem argumentação $0^{38}$ e "busca uma relação distinta - infrequente, irritante - entre percepção e comunicação $e$ isso é unicamente o que se comunicará" ${ }^{39}$

A (auto)constituição da arte como um sistema funcionalmente fechado obedece a uma sucessiva especificação de sua extensão denotativa, de um conceito amplo - ars ou téchne como "aquilo que foi elaborado perseguindo uma finalidade", como criação humana, artificial, em contraposição a natura ou physis, como "aquilo que por si mesmo surge e desaparece" - até um fechamento autopoiético contra a ingerência de fins religiosos, políticos, pedagógicos como determinantes da obra de arte, pelo que se chega a declarar "como válido unicamente a arte bela cuja finalidade própria seja não perseguir finalidade alguma", ao que se refere com a fórmula paradoxal de ser um "fim em si mesmo". ${ }^{40} \mathrm{~A}$ arte é caracterizada, portanto, como uma forma peculiar de articulação de símbolos, com preferência por distinções ambíguas, geradoras de sentidos conotativos, mediatos, imprecisos, latentes ${ }^{41}$ (incluindo-se aí a arte literária); $; 2$ a arte insere-se no universo do simbólico, que "implica uma linguagem ou discurso no qual há uma mudança do significado para uma diferente esfera de comunicação", na qual se valoriza

\footnotetext{
Id., p. 41.

Id., p. 44.

Id., p. 46 (grifos no original).
}

40 Id., p. 47. Luhmann (Id., p. 49) destaca: "Mas então a pergunta é: e isso, para que? A ausência de uma resposta firme ou a constante mudança de respostas no curso da história não constituem nenhuma objeção [à arte como sistema funcionalmente diferenciado e autopoiético]: é algo típico, sobretudo para a arte maior, significativa". Por outro lado (Id., p. 315), "[s]e tudo fosse aceitável (e nada fosse inaceitável) não seria possível distinguir entre arte e não arte. Sem essa distinção não seria possível inclusive sabotar a distinção mesma".

${ }^{41}$ Tais seriam os caracteres vinculados à expressão simbólico, em geral, conforme NEVES, Marcelo. $A$ constitucionalização simbólica. São Paulo: Martins Fontes, 2007, esp. p. 22-23.

42 Diferentemente do que predomina no uso não artístico da linguagem (linguagem natural, lógica, científica, etc.), na literatura "[o] sentido se transmitirá através das conotações - e não das denotações; através da estrutura ornamental das referências (que reciprocamente se limitam e que se exibem em forma de palavras), mas não através do sentido lógico da frase, não através do sentido proposicional das afirmações. O texto artístico se distingue da fisionomia do texto normal - o qual, como se diz no jargão pós-moderno, procura ser 'readerly' e com isso deixa alocado o leitor no papel passivo de só entender -; distingue-se porque [o texto literário] exige do leitor um 'rewriting', uma nova reconstrução do texto. Ou, com outras palavras: o texto artístico não se empenha em repetir automaticamente o sentido conhecido do signo, senão busca - apesar da advertência - romper com os automatismos e fazer com que o entendimento de um texto se prolongue até a obra de arte. [...] Não se quer dizer outra coisa quando afirmamos: as palavras se utilizam como meio e não com vistas a um sentido inequívoco-denotativo. [...] Em lugar disso, a eleição das palavras como meio obriga a uma combinação inusualmente densa e constante de autorreferência e heterorreferência. As palavras têm ('significam') um significado de uso normal, por isso remetem a algo diferente e não só a si mesmas. Mas também têm (e 'significam') um sentido específico dentro do texto, porquanto realize e mantenha as recursões deste". LUHMANN, Niklas. El arte de la sociedad. cit., p. 50-52. 
a "significação imprecisa, que é adicionada ao seu manifesto e imediato sentido [...] e prevalece sobre este". ${ }^{43}$ Trata-se de "um tipo específico de comunicação que se serve da capacidade de percepção ou da imaginação e que, apesar disso, não se confunde com o mundo percebido normalmente [...], produz uma fascinação que, ao modificar o estado do sistema, converte-se em informação - como difference that makes a difference (Bateson). E isso precisamente é comunicação: se não, então o que é?"’ ${ }^{44}$

$\mathrm{O}$ código do sistema artístico é belo/feio ${ }^{45}$ e, ao contrário da Antiguidade, ${ }^{46}$ hoje pode ser concebido independentemente de seus efeitos morais ${ }^{47}$ - diferentemente

43 NEVES, Marcelo. The symbolic force of human rights. Philosophy \& Social Criticism, Thousand Oaks, v. 33, n. 4, 2007. p. 413.

44 LUHMANN, Niklas. El arte de la sociedad. cit., p. 52-53 (grifos no original).

45 Id., p. 317: "Na estética clássica, os valores do código da arte se designaram como belo/feio, e nas obras de arte se admitiam também objetos feios". Para Luhmann (Id., p. 315, grifo no original): "Não obstante, um código deveria gerar ademais programas que 'operacionalizem' a preferência do sistema no plano das operações. E precisamente neste aspecto, a distinção arte/não arte segue sendo tão insatisfatória quanto a distinção belo/feio". Por isso: “Atualmente é cada vez mais difícil conservar - contra os contínuos protestos do sistema mesmo - estas designações (belo/feio) para designar o valor positivo (ou negativo) do código. [...] Por conseguinte, aparentemente seu problema radica em que relacionam critérios de avaliação com características descritivas das obras de arte particulares - e, inversamente, inferem critérios generalizáveis a partir de ditas características. Não obstante, com esses pressupostos não é possível separar o nível da codificação do da programação - o que é típico dos sistemas funcionais da sociedade moderna, dada a ‘positivação' de seus programas. [...] Em todo caso, a Tradição não pôde distinguir entre função e codificação como formas distintas de determinação da particularidade de um sistema." (Luhmann, 2005a: 319, grifos no original). Segundo analisa Luhmann (Id, p. 331, 333, grifo no original): “A separação entre codificação e programação (e com isso o reordenamento da auto-organização da arte) começa apenas a abrir-se espaço quando a novidade se considera indispensável como requisito das obras de arte; quer dizer, quando se impede de copiá-lo. [...] A novidade se maneja como condição de que se goste de algo e isso serve para que a arte se delimite: naturalmente, não se gosta nem na religião, nem na política, nem no direito". Hoje, "[d] epois do fracasso da busca dos critérios 'objetivos', a objetividade do belo pode-se conceber tão só como círculo - e com isto se deixa à história a decisão acerca de que formas convencem correspondentemente como belas" (Id., p. 321). Ao longo da evolução da(s) sociedade(s), atinge-se a autonomia funcional da arte quando "[t]oda correspondência ponto por ponto entre o sistema e o entorno - como se pode observar nas sociedades tribais com o simbolismo da morte - está interrompida" (Id., p. 379). Por fim, Luhmann (Id., p. 324-325) acaba concluindo que "[n]ão existe [...] alternativa convincente para o belo/feio".

46 Sócrates afirmou: "E segue sendo correto que o bem, o belo e o justo continuam sendo a mesma coisa". PLATÃO. Críton ou do dever. In: OS PENSADORES. Platão. São Paulo: Nova Cultural, 1999. p. 107.

47 LUHMANN, Niklas. El arte de la sociedad. cit., p. 316: "O belo não necessariamente deve coincidir com o moralmente bom, e inclusive não deve adquirir nenhuma força persuasiva a partir de uma coincidência deste tipo, senão deve convencer como arte mesma". 
do que ocorre no sistema dos meios de comunicação de massa. ${ }^{48}$ Para Luhmann, ${ }^{49}$ são "poucos (e frouxos) os acoplamentos estruturais entre o sistema da arte e outros sistemas"; há o "mercado de arte como acoplamento estrutural entre o sistema da arte e a economia", mas "[c]omparado com as relações internas de outros sistemas - direito e política, ciência e economia - o sistema da arte carece de tais acoplamentos".

\subsection{O sistema dos meios de comunicação de massa}

O conceito luhmanniano de meios de comunicação (de massa) cobre "todas as instituições da sociedade que servem de meios técnicos de reprodução para a difusão da comunicação", abrangendo os meios impressos (como livros, jornais, revistas), sonoros, audiovisuais, informáticos, etc., sendo "decisivo, em todos os casos, o fato de não poder ocorrer, nas pessoas que participam, nenhuma interação entre emissor e receptor [ou melhor, na terminologia luhmanniana, entre alter e ego]. A interação torna-se impossível pelo fato de ocorrer a interposição da técnica e isso tem consequências de longo alcance que definem para nós o conceito de meios de comunicação". ${ }^{50}$

A autoconstrução do sistema dos meios de comunicação de massa como um sistema funcionalmente diferenciado e autopoiético tem por base a alta liberdade de comunicação que é proporcionada por se interromper-por meio das tecnologias de difusão - o contato direto entre alter e ego (interação) como condição para a comunicação, o que gera um excedente de informação de tal nível que demanda a auto-organização de um sistema próprio, que construa a própria realidade ${ }^{51}$ segundo seus programas (especialmente os temas), código (informação/não informação ou informativo/não informativo) $)^{52} \mathrm{e}$

48 A diferenciação entre arte trivial e não trivial, com a identificação desta ao entretenimento, estaria "na problematização da informação ou, mais precisamente, na questão se ao mesmo tempo se observa também a autorreferência da informação. Se a informação for autorreferencial, então ela será reconhecida na rede recursiva da obra de arte, quer dizer, ela estará relacionada à questão: o que a seleção exatamente dessa informação (e de nenhuma outra) contribui para o jogo de formas da obra de arte. Se for trivial, então a informação será vivenciada apenas como surpresa, como uma supressão agradável de incertezas ainda existentes [...]. Aqui mal se pode falar de acoplamentos estruturais recíprocos, pos não se pode ver como a arte poderia se aproveitar do fato de ser trivializada como entretenimento - a não ser no sentido de ela impelir na direção das formas que são cada vez menos apropriadas como entretenimento, isto é, no sentido da pressão para manter-se na diferença. Mas observa-se que o entretenimento escora-se ao sistema da arte e fica imprecisa a caracterização como arte ou como entretenimento e fica a cargo do observador essa classificação". LUHMANN, Niklas. A realidade dos meios de comunicação. cit., p. 116-117.

49 LUHMANN, Niklas. El arte de la sociedad. cit., p. 397.

50 LUHMANN, Niklas. A realidade dos meios de comunicação. cit., p. 16-17 (grifos no original).

$51 \quad$ Id., p. 17, 36-37.

52 Id., p. 39. Para Luhmann (Id., p. 42-44): "Uma notícia, quando usada pela segunda vez, mantém certamente seu sentido, mas perde seu valor informativo. Se a informação é utilizada como valor do código, isso significa que as operações do sistema transformam contínua e necessariamente informação em não informação. Ultrapassar os limites de um valor para um valor oposto ocorre automaticamente com a simples autopoiese do sistema. O sistema reintroduz constantemente o próprio output, quer dizer, o conhecimento 
função - "produção contínua e processamento de irritações", 53 fornecendo à sociedade um substrato comum de informações, dada a alta redundância que os meios de comunicação de massa produzem ${ }^{54}$ e a simplificação da realidade por eles construída (pela constante atribuição de ações a pessoas e pela avaliação moral das condutas, por exemplo). ${ }^{55}$ Se não é possível dar-se a conhecer o mundo e orientar a ação de forma generalizada pela ciência ou pelo direito, por exemplo, e se não se pode deixar uma base de conhecimentos para a vida em sociedade, "na moderna sociedade mundial", restritivamente ao "conhecimento cotidiano meramente local", é necessário o surgimento de um sistema que forneça uma construção da realidade simplificada, mas abrangente, que acaba por regular a memória (lembrança e esquecimento) da sociedade e por irritar seus múltiplos subsistemas. ${ }^{56}$

Deve-se observar que, embora haja diferentes critérios para alocação do código sistêmico fundamental informação/não informação (isto é, para a programação, no sentido sistêmico, dos meios de comunicação) conforme se diferenciem as modalidades da programação (no sentido usual das seções de um periódico ou da grade de programas de televisão) - notícias e reportagens, publicidade, entretenimento ${ }^{57}$-, a unidade do sistema dos meios de comunicação não é quebrada por sua unidade de código-base e função. ${ }^{58}$ Por exemplo, a distinção verdadeiro/falso, código de preferência do sistema científico,

de fatos em si mesmo novamente, e o faz pelo lado negativo do código, como não informação; e, o fazendo, ele se força com isso a prover sempre novas informações. Em outras palavras, o sistema envelhece-se a si mesmo. Poder-se-ia, por isso, pensar que ele utiliza o código novo/velho quando não há outras razões objetivas para não tornar pública a informação. Esse automatismo não exclui naturalmente a possibilidade da repetição. Principalmente a publicidade faz uso disso. Mas nesse caso precisa ser usada a figura reflexiva do valor informativo da não informação como indicador da importância e de o fato ser digno de lembrança: o mesmo anúncio é várias vezes repetido para que dessa forma os leitores que notam a repetição estejam informados do valor do produto". Prosseguindo, Luhmann (Id., p. 44-5, grifos no original) nota: "Da mesma forma que a economia, diferenciando-se de forma autofortificada com base nos pagamentos em dinheiro, produz incessantemente a necessidade de substituir o dinheiro gasto pelo novo, de forma semelhante os meios de comunicação produzem necessidade de substituir a informação redundante por nova informação: fresh money e new information são os motivos centrais da moderna dinâmica social".

53 Id., p. 159

$54 \quad$ Id., p. 44.

55 Id., p. 63-65.

56 Id., p. 160. “Os meios de comunicação, portanto, não são meios no sentido de transportarem informações dos que sabem àqueles que não sabem. Eles são meios à medida que disponibilizam um saber de fundo e continuam sempre a desenvolvê-lo; um saber que se pode tomar como base na comunicação. A diferença constituinte não é saber/não saber mas medium e forma. O medium disponibiliza um campo de possibilidades gigantesco mas limitado, do qual a comunicação pode escolher formas ao se fixar temporariamente em determinados conteúdos" (Id., p. 115, grifos no original).

57 Id., p. 113-114 (grifos no original): “[...] pode-se dizer que a contribuição de todas as três formas de comunicação medial, e nisso elas estão de acordo, consiste em criar pressupostos para a comunicação seguinte, que não precisam ser expressamente comunicados junto. Isso vale tanto para o estado de se estar atualização em informação como para o estar atualizado em cultura, no que se refere aos julgamentos sobre valores, às formas de vida, ao que está e ao que não está na moda".

$58 \quad$ Id., p. 51. 
não é primária e fundante para os meios de comunicação. ${ }^{59}$ Já na relação com uma esfera não fechada operacionalmente a ponto de se constituir como sistema autopoiético - caso da moral -, o sistema dos meios de comunicação pode guardar relações mais próximas, reproduzindo, senão o conteúdo, pelo menos a forma moral, com base na "distinção entre a boa e a má ação": 60 a "cultura da televisão", que produz uma realidade própria, moralmente codificada, potencializa o consenso em torno de reduções da complexidade ao bem e ao mal. ${ }^{61}$ Porém, afora os sistemas da economia e da política, e afora a moral, os acoplamentos estruturais entre o sistema dos meios de comunicação e outros sistemas, como o esporte, a arte, a ciência e o direito, não seriam mais que marginais, para Luhmann. ${ }^{62}$

Como todo sistema funcional autopoiético, mas com maior difusão e impacto na sociedade, o sistema dos meios de comunicação observa a realidade e produz-lhe uma duplicação, re(a)presentando a sociedade a ela própria, na forma como este sistema, concebendo-se por distinguir-se de seu ambiente, pratica autorreferência e hetorreferrência. ${ }^{63}$

Assim, os meios de comunicação de massa produzem os "valores próprios' da sociedade moderna, a saber, aquelas orientações relativamente estáveis nas esferas cognitiva, normativa e avaliativa [...]", ${ }^{64}$ as quais são tomadas como pressuposto da comunicação em sociedade, possibilitando - e restringindo - o dissenso. ${ }^{65}$ Em sua construção da realidade, operam criando ideologias, condensando valores em uma

59 Id., p. 56: "Os meios de comunicação interessam-se por aquilo que é verdadeiro só sob condições fortemente restritivas, condições que se distinguem claramente daquelas da pesquisa científica".

60 Id., p. 63 (grifo no original).

61 LUHMANN, Niklas. La sociedad de la sociedad. cit., p. 895.

62 LUHMANN, Niklas. A realidade dos meios de comunicação. cit., p. 117.

63 Id., p. 20-21.

64 Id., p. 161.

65 Id., p. 162. "Como sempre, os meios de comunicação dão uma coloração especial àquilo que noticiam e à forma como noticiam; assim, decidem sobre o que deve ser esquecido, o que pode ser significativo apenas no momento e o que deve permanecer na lembrança. [...] Com as identidades continuamente renovadas dessa forma preenche-se a memória social. Memória, nesse caso, não deve ser entendida como armazenamento de circunstâncias ou acontecimentos passados. Os meios de comunicação e outros sistemas cognitivos não podem se sobrecarregar com tais coisas. Trata-se antes de um contínuo discriminar entre o esquecer e o lembrar. [...] Pois sem memória nada pode aparecer como 'novo' (como desviante), e sem experiências desviantes nenhuma memória se forma." (Id., p. 66-67, 72-73, grifo no original). Ao procurar definir a "função social dos meios de comunicação", Luhmann (Id., p. 114, grifos no original) avalia que esta "não se encontra na totalidade das informações sempre atualizadas (quer dizer, não no lado tomado como positivo do código) mas na memória produzida por meio disso. Para o sistema social, a memória consiste no fato de, em cada comunicação, se poder tomar como conhecidas algumas suposições determinadas sobre a realidade, sem precisar introduzi-las ou justificá-las expressamente. A memória colabora em todas as operações do sistema social, quer dizer, em todas as comunicações; ela ajuda no controle ininterrupto de consistência, olhando de relance o mundo conhecido e excluindo como improváveis as informações muito ousadas". 
narrativa de bases morais; daí que a simplicidade da realidade produzida pelos meios de comunicação encubra paradoxos e limites. ${ }^{66}$

Pela própria seleção de temas e esquematização das descrições por sua subsunção a temas, os meios de comunicação constroem uma realidade própria com sentido interno (coerência), trazendo em sua própria comunicação sistêmica, observações e descrições de auto e heterorreferência, informação esta sobre as diversas esferas da sociedade - já que os temas acoplam estruturalmente os meios de comunicação a outros sistemas funcionais - que o sistema dos meios de comunicação torna disponível ao conhecimento do amplíssimo público que constitui seu ego. Seu público é definido na base de certo nível de conhecimento pressuposto para a compreensão da informação. ${ }^{67}$

A construção da realidade pelos meios de comunicação, com sua seleção altamente específica das comunicações, leva a focos bastante "etnocêntricos", 68 a universalizações de particularidades que caracterizam classicamente a produção da ideologia no sentido marxista e gramsciano. É com a construção da realidade operada pelos meios de comunicação que a sociedade se orienta predominantemente em seus vários âmbitos, o que inclui em certo grau ciência e a produção da teoria:69 "O que se sabe sobre a sociedade se sabe pelos meios de massas". ${ }^{70}$ A diferenciação autofortificada de um sistema funcional próprio dos meios de comunicação de massa aumenta os excedentes de informação e a pressão por seleção de informação (a ser tornada conhecida), que é regida dominantemente pelos critérios desses meios de comunicação, os quais moldam a opinião pública. ${ }^{71}$ Nota-se que o conceito de "opinião pública" não aponta para o consenso e integração da sociedade, mas apenas funciona como referência que possibilita uma observação de segundo grau (observar observadores). ${ }^{72}$

${ }^{66}$ Id., p. 65-66 (grifos no original): “A discussão das ações e das pessoas assume a função especial de encobrir os limites do sistema e, com isso, as distinções do modo de operação de sistemas diferentes. Conceitos como ação e pessoa não podem ser limitados nem a processos sociais, nem a processos de consciência, tampouco a processos bioquímicos ou neurofisiológicos. Eles pressupõem, antes, que todos prestem uma contribuição à ação e ao processo de tornar-se pessoa (zum Personsein), sem que se possa averiguar, em relação a esses conceitos, como ocorre esse agir conjunto. Essa indistinção está claramente a serviço da pressa da comunicação. Mas, ao mesmo tempo, ela também controla aquilo que como comunicação sucessiva, pode ser acoplado - e aquilo que não pode ser acoplado - à comunicação".

${ }_{67}$ Id., p. 30-31. Deve-se notar: "Na base de todas as seleções - e isso vale tanto para a comunicação cotidiana quanto para aquela efetivada pelos meios de comunicação de massa - há um agir integrado da condensação, da confirmação, da generalização e da esquematização, que não se acha dessa maneira no mundo externo sobre o qual se comunicam coisas" (Id., p. 71, grifos no original). Quanto ao público alvo dos meios de comunicação, este parece desenhar-se como um "construto social [...] do "ser humano cognitivamente mais ou menos informado, apto a decisões, moralmente responsável'” (Id., p. 125).

68 LUHMANN, Niklas. La sociedad de la sociedad. cit., p. 871.

69 Id., p. 873.

70 Id., p. 655

71 Id., p. 869-870.

72 Id., p. 870 
A autopoiese e o fechamento operacional do sistema dos meios de comunicação baseia-se na seleção e processamento de informações segundo o código informação/não informação e por programas que enfatizam o valor da surpresa, ${ }^{73}$ o que gera a construção de realidade própria deste sistema, cuja função é, em certo sentido, a de ser a memória da sociedade (determinando o fluxo do que deve ser lembrado e esquecido), ${ }^{74}$ absorvendo "incerteza na produção e reformulação das descrições de mundo e de sociedade". ${ }^{75}$ Tal sistema funcional molda a opinião pública, ${ }^{76}$ como "médium de descrição do mundo e de autodescrição da sociedade moderna". ${ }^{77}$ Conforma, assim, o senso comum, tendo crescente importância na simplificação da semântica sobre a sociedade, em contraposição ao sistema científico, que gera crescentemente mais incertezas do que certezas com o aumento da complexidade de suas redes recursivas. ${ }^{78}$

Dentro de uma sociedade mundial desigual, os meios de comunicação de massa fornecem uma base de conhecimento igual e padronizam as preferências artísticas, os gostos e demais referências culturais. A publicidade, por exemplo, como organização do "ato de enganar conscientemente" tem como função latente "produzir e consolidar critérios de bom gosto para aquelas pessoas que deles carecem; quer dizer, suprir de segurança o juízo a respeito das qualidades simbólicas de objetos e modos de conduta". ${ }^{80}$

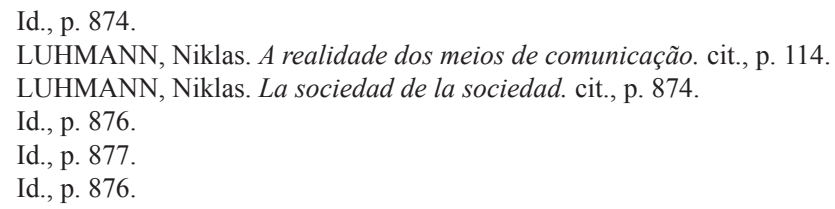

LUHMANN, Niklas. A realidade dos meios de comunicação. cit., p. 84. "A publicidade tenta manipular, ela trabalha de forma pouco sincera e pressupõe que isso seja um pressuposto. Ela assume, por assim dizer, o pecado mortal dos meios de comunicação - como se dessa maneira todos os demais programas pudessem ser salvos. Talvez seja esse o motivo pelo qual a publicidade jogue com cartas abertas. Aqui dissolvem-se com um só golpe as questões que fazem suspeitar dos motivos que acabamos de discutir. A publicidade declara seus motivos, mas refina e encobre frequentemente seus meios. [...] A atenção consciente só é solicitada num período extremamente curto, de tal forma que não sobra nenhum tempo para uma apreciação crítica ou para uma decisão pensada. [...] Entretanto, isso não muda nada no fato de que ninguém se engana em relação à intenção da publicidade, ao motivo de sua comunicação" (Id., p. 83-84).

80 LUHMANN, Niklas. La sociedad de la sociedad. cit., p. 875 (referindo-se à análise de Bourdieu). "Entre as funções latentes mais importantes da publicidade (que são estrategicamente utilizadas como tais) está a de prover as pessoas que não possuem gosto com algum gosto. Depois que ficou provado como sendo impossível transformar formação cultural em dinheiro, a possibilidade contrária, a de fazer o dinheiro aparecer como formação cultural - e, naturalmente, em considerável medida, a crédito - tem de qualquer forma certas chances de sucesso. Essa função refere-se à qualidade simbólica dos objetos, que é parcialmente expressa no seu preço mas não o suficiente. [...] a classe alta mantém-se naquilo que considera digno de desejo e de demonstração de acordo com o que é ditado pela publicidade, e isso principalmente porque o mercado não oferece nada de muito diferente, mas, em todo o caso, diferencia pelo preço". LUHMANN, Niklas. A realidade dos meios de comunicação. cit., p. 87. 


\section{Cultura e comunicabilidade}

Importa aqui notar a diferença de grau de inclusão/exclusão das pessoas na sociedade e em seus sistemas parciais e o que tal diferença pode importar em termos das comunicações em cada sistema funcional. A total exclusão da sociedade constitui a situação em que o sujeito é totalmente incapaz de se comunicar (via de regra, quando perde a habilidade de usar a linguagem). Sem poder dar a conhecer comunicações, tampouco compreendê-las, a pessoa chega à condição desumanizadora em que sequer é reconhecida como pessoa pela sociedade, sendo marginalizada como alguém fora desta, existindo apenas como indivíduo, como corpo (sistema orgânico). ${ }^{81}$ Sem poder, faticamente, comunicarse, o indivíduo também tem extremamente reduzida a probabilidade de ser tomado em consideração na sociedade, de ser referido tácita ou explicitamente nas comunicações travadas no âmbito das esferas comunicativas, inclusive dos sistemas funcionais. Nesse caso, o código inclusão/exclusão nem atua como metacódigo do sistema parcial, pois não sofre re-entry no sistema: os totalmente excluídos nem são parte da economia, nem da sociedade. E muitas vezes isso nem é uma consideração pressuposta das diversas comunicações, pois sequer a referência tácita a essa condição (dos totalmente excluídos) é tomada em muitos dos discursos sistêmicos. Por isso, os sistemas tendem a produzir suas autodescrições, operar segundo seus códigos e produzir seus programas sem considerar que não valem, absolutamente, para essa parcela não desprezível, sequer quantitativamente, da humanidade - este é um problema evidente na dogmática dos direitos fundamentais, principalmente quando distingue liberdades fundamentais e direitos sociais. ${ }^{82}$

Por outro lado, os subincluídos já são capazes de serem levados em conta nas comunicações, já podendo ser referidos nos discursos da economia, da política, da educação. Podem também participar como produtores das comunicações nesses âmbitos, em certo grau, ainda muito reduzido. Mas, de fato, a semântica predominante produzida por cada sistema, a realidade construída por cada um pressuposta, não conta com contribuições homogêneas das falas de todas as pessoas, nem mesmo com uma - sempre relativa - igualdade entre os incluídos em sentido amplo. É forçoso reconhecer que, em geral, as informações compreendidas que predominam qualitativa e quantitativamente resultam de comunicações dadas a conhecer pelos que são bem incluídos ou sobreincluídos em cada sistema, ainda que não necessariamente em todos (ter, poder, verdade, lícito são meios que não necessariamente se detém em conjunto na sociedade moderna, como

81 LUHMANN, Niklas. La sociedad de la sociedad. cit., p. 501.

82 Id., p. 841-842: “Toda a maquinaria dos direitos de liberdade e de suas garantias constitucionais está construída sobre a hipótese de que existe um grande âmbito de possibilidades de ação no qual o indivíduo pode atuar de forma útil para si mesmo e lograr consequências neutras para os demais (quer dizer: o 'ótimo paretiano') ou, caso necessário, pode encontrar consenso contratual’. 
assinala Luhmann). ${ }^{83}$ Há, portanto, um desnível quantitativo entre os três momentos da comunicação: informação, mensagem e compreensão.

Evidente é, dessarte, a predominância qualitativa e quantitativa das comunicações de certas pessoas e países quando se trata de analisar os conteúdos das comunicações predominantes em cada âmbito da sociedade funcionalmente diferenciada, principalmente em seus sistemas funcionais. No plano pessoal, há considerável proporcionalidade entre o grau de inclusão da pessoa no sistema e o nível de difusão e penetração de suas ideias no sistema respectivo - nota-se que o grau de inclusão sistêmica da pessoa pode ser mensurado pelo pertencimento a organizações de prestígio, por exemplo: a condição de membro também aloca positivamente status a quem a ostentar. ${ }^{84}$ Ao lado da dimensão pessoal, surgem diferenças de predominância das comunicações em cada sistema social (em regra, simultaneamente em vários sistemas) entre os diversos países, o que torna até possível a observação da diferenciação centro/periferia (enquanto tipos ideais) em sistemas como a ciência..$^{85}$

Ao lado das diferenças pessoais e espaciais, vale também considerar outras diferenças que - mesmo de forma implícita, tácita, pressuposta - culminam com o maior apelo e a maior difusão de certas comunicações (com seus conceitos, sua linguagem, seus pressupostos). Sem desconsiderar a existência dessas outras referências que subjazem às comunicações e demais fatores que fazem umas terem maior "sucesso de público" e audiência do que outras, cabe aqui analisar as disparidades quanto a pessoas e países, incluindo a seguir a dimensão das culturas - comunidades culturais enquanto loci móveis compartilhadores de certa base comum de compreensões de mundo e representações simbólicas. Assim, pode-se propor que há disparidades de "poder de comunicação" entre pessoas e, analogamente, entre países e entre culturas. Embora cabível esse uso na perspectiva de uma teoria crítica dos sistemas, ${ }^{86}$ Luhmann e outros autores da mesma vertente rejeitam a vinculação do medium poder a comunicações fora do sistema político e das organizações. ${ }^{87}$ Por outro lado, a referência a "capacidade de comunicação" poderia

$83 \quad$ Id., p. 281-282.

$84 \quad$ Id., p. 658.

85 É o que postula Fabrício Monteiro Neves (NEVES, Fabrício Monteiro. A diferenciação centro-periferia como estratégia teórica básica para observar a produção científica. Revista de Sociologia Política, Curitiba, v. 17, n. 34, 2009, esp. p. 248), principalmente a partir de NEVES, Marcelo. Entre Têmis e Leviatã: uma relação difícil: o Estado Democrático de Direito a partir e além de Luhmann e Habermas. 2. ed. São Paulo: Martins Fontes, 2008. p. 226-228.

86 Nesse sentido, Fischer-Lescano (2010, p. 169) cita Teubner: "O 'político' aparece então como tomada de decisão num contexto de indefinição que ultrapassa o sistema político, assim como a incomensurabilidade de sentido em arranjos antagônicos". Isso permite ver que, "apesar do monopólio estatal do uso da força, os processos de poder ocorrem além da política". FISCHER-LESCANO, Andreas. A teoria crítica dos sistemas da Escola de Frankfurt. Tradução de Rúrion Melo. Novos Estudos Cebrap, São Paulo, v. 86, 2010. p. 169.

${ }^{87}$ Em contraste com a citação de Teubner por Fischer Lescano, em outro artigo Graber e Teubner consideram 
ser mal compreendida, envolvendo apenas uma parte do problema-os sujeitos totalmente incapazes de se comunicar, identificados àqueles totalmente excluídos de determinado sistema ou da sociedade como âmbito máximo das comunicações. Afinal, prefere-se o conceito de "comunicabilidade", a designar os diferentes graus de marginalidade ou predominância qualitativa e/ou quantitativa das comunicações de pessoas, países, culturas (ou qualquer outro grupo delimitável: organizações, por exemplo) em um dado espaço em regra, tomado como referência o espaço global.

Destarte, em cada esfera comunicacional da sociedade, notadamente nas sistemicamente estruturadas (sistemas funcionais), a maior comunicabilidade de certas pessoas lhes permite instituir-se como "discurso competente" 88 daquele sistema, definindo, pela capacidade de dar a conhecer suas ideias e fazê-las compreendidas, o padrão comunicacional que acaba por discernir o que é relevante de ser comunicado naquele sistema e forma seus pressupostos, com o que se limita o enlace de comunicações posteriores a essa rede recursiva já construída predominantemente pelo que disseram os que podem falar mais ou ser melhor ouvidos - o que pressupõe uma maior inclusão, dos cientistas, por exemplo, não-só no sistema da ciência (o que significa, para estes, maior disponibilidade do meio "verdade"), mas também no sistema dos meios de comunicação em massa, acoplados estruturalmente à economia pelo comércio e indústria de livros, por exemplo.

É certo que as diferenciações internas das pessoas nos sistemas podem ser, em certa medida, funcionais ao seu desenvolvimento. Mas é necessário pluralizar os discursos inerentes a cada um (dos sistemas), de modo a aumentar a sua complexidade e as possibilidades dentre as quais escolher - o que reforça, inevitavelmente, a necessidade de seleção; por outro lado, os limites sistêmicos podem ser ampliados se estruturada esta complexidade.

que "analogias estruturais com o poder do Estado" representam "uma obsessão com o fenômeno do poder que tende a negligenciar outros meios de comunicação [sistêmicos] como ameaças à autonomia individual e social". GRABER, Christoph Beat; TEUBNER, Gunther. Art and money: constitutional rights in the private sphere? Oxford Journal of Legal Studies, Oxford, v. 18, n. 1, 1998. p. 70.

88 CHAUI, Marilena. Cultura e democracia: o discurso competente e outras falas. 12. ed. São Paulo: Cortez, 2006. p. 19: "O discurso competente é aquele que pode ser proferido, ouvido e aceito como verdadeiro ou autorizado (estes termos agora se equivalem) porque perdeu os laços com o lugar e o tempo de sua origem. Assim, não é paradoxal nem contraditório em um mundo como o nosso, que cultua patologicamente a cientificidade, surgirem interdições ao discurso científico. [...] O discurso competente é o discurso instituído. É aquele no qual a linguagem sofre uma restrição que poderia ser assim resumida: não é qualquer um que pode dizer a qualquer outro qualquer coisa em qualquer lugar e em qualquer circunstância. O discurso competente confunde-se, pois, com a linguagem institucionalmente permitida ou autorizada, isto é, com um discurso no qual os interlocutores já foram previamente reconhecidos como tendo o direito de falar e ouvir, no qual os lugares e as circunstâncias já foram predeterminados para que seja permitido falar e ouvir e, enfim, no qual o conteúdo e a forma já foram autorizados segundo os cânones da esfera de sua própria competência". 
A diferenciação funcional organiza-se pela complementaridade de papéis, ${ }^{89}$ e a comunicação pressupõe assim certa assimetria entre os interlocutores. Em uma sociedade diferenciada funcionalmente, mas, ao mesmo tempo, razoavelmente includente, não é preciso ser igual em todos os sistemas (deter igualmente os meios ter, poder, verdade, etc.), mas as disparidades no plano pessoal tendem a ser disfuncionais e desdiferenciantes para os diversos sistemas. Por isso: "O problema de uma sociedade complexa vem a ser o de prover uma desintegração suficiente", ${ }^{90}$ ou seja, fazer com que a participação (e o grau de participação) em cada um dos sistemas torne-se mais próximo de uma escolha entre várias oportunidades do que de uma determinação alienada a instâncias inacessíveis.

De fato, a diferente comunicabilidade permite a algumas ideias e seus autores cruzarem a fronteira performativa da comunicação, passando da mera informação (report) ao comando ("dá-la [a informação] a conhecer com pretensões de aprovação"). ${ }^{91}$ Certas ideias presidem semânticas que, como "vantagens de sentido dignas de ser conservadas", produzem uma ulterior distinção entre seu uso correto ou errado, o que gera "a necessidade de se dispor de expertos em interpretação - os quais custodiam o uso correto, 'ortodoxo' do texto, além de derivar seu prestígio social da qualidade deste mesmo. Dessa maneira é muito fácil que o sentido correto do texto chegue a adquirir uma qualidade normativa", conservando-se mesmo se viger menos que o uso (des)qualificado como incorreto. ${ }^{92}$ Para poder comunicar-se no sistema, o indivíduo tem que aderir aos discursos sistêmicos, dado que a falta dessa sociabilização o exclui definitivamente de um ou outro sistema; e, então, praticamente de todos, ${ }^{93}$ dada a reação em série da exclusão como fator de integração (conjunção sistêmico-funcional), no sentido de Luhmann. ${ }^{94}$

Essa diferenciação entre as comunicabilidades de certas pessoas ou ideias, embora ideologicamente velada, ${ }^{95}$ existe e é fortemente condicionante das distinções que os sistemas tomam como pressuposto em suas operações (comunicações). Essa invisibilização está conjugada à mobilidade das posições de uma pessoa quanto ao seu

89 LUHMANN, Niklas. La sociedad de la sociedad. cit., p. 586.

$90 \quad$ Id., p. 479.

$91 \quad$ Id., p. 908.

92 Id., p. 704. Para Chauí: "O que é o discurso competente enquanto discurso do conhecimento? Sabemos que é o discurso do especialista, proferido de um ponto determinado da hierarquia organizacional. Sabemos também que haverá tantos discursos competentes quanto lugares hierárquicos autorizados a falar e a transmitir ordens aos degraus inferiores e aos demais pontos da hierarquia que lhe forem paritários. Sabemos também que é um discurso que não se inspira em ideias e valores, mas na suposta realidade dos fatos e na suposta eficácia dos meios de ação. [...] A condição para o prestígio e para a eficácia do discurso da competência como discurso do conhecimento depende da afirmação tácita e da aceitação tácita da incompetência dos homens enquanto sujeitos sociais e políticos". CHAUI, Marilena. Cultura e democracia: o discurso competente e outras falas. cit., p. 23 (grifos no original).

93 Id., p. 24-25.

94 LUHMANN, Niklas. La sociedad de la sociedad. cit., p. 500.

95 Id., p. 855. 
grau de inclusão em cada sistema, o que possibilita discernir a sociedade diferenciada preponderantemente por um critério funcional (mas não-só) de seus tipos anteriores: nas sociedades estratificadas, "[p]or mais diferente que seja a base econômica que distingue a um estrato superior, dificilmente se pode negar o fato de que existe um estrato alto e de que sua existência e distinção são consideradas no acontecimento comunicativo". ${ }^{96}$

Se se adotar a fórmula da "sociedade da informação" dentro do conceitual luhmanniano, ter-se-ia que admitir que na sociedade atual importa mais a informação em si do que sua compreensão e sua veiculação, e esta ênfase, ao diminuir a relevância deste componente comunicacional intermediário (dar a conhecer), significaria entender que na sociedade moderna têm importância muito reduzida a vinculação da comunicação a quem a promove, isto é, a referência ao status e posição social do interlocutor. ${ }^{97}$

De fato, a diferente comunicabilidade das pessoas, no plano da cultura, coloca-se na desautorização de boa parcela destas quanto a participarem dessa esfera de comunicação enquanto produtoras de conhecimento e de cultura. ${ }^{98} \mathrm{Na}$ história do sistema, enquanto memória de suas operações, apenas algumas comunicações e interlocutores permanecem enquanto referências.

A comunicabilidade ganha especial relevância em referência ao sistema artístico, já que a linguagem e a arte possibilitam o acoplamento estrutural entre os sistemas psíquicos (os seres humanos, fora da sociedade) e o sistema social (sociedade). A possibilidade de produção artística aumenta, pois, o potencial de irritação da sociedade

$96 \quad$ Id., p. 538.

97 Id., p. 864.

98 CHAUI, Marilena. Cidadania cultural: o direito à cultura. São Paulo: Perseu Abramo, 2006. p. 9: “Sob o primeiro aspecto - saber de especialistas -, a cultura é algo que alguns fazem e possuem enquanto os demais a recebem passivamente. Com essa perspectiva, simplesmente aderimos à forma atual da ideologia, a ideologia da competência, que divide a sociedade entre aqueles que sabem, e por isso mandam, e aqueles que não sabem, e por isso obedecem. [...] Sob o segundo aspecto - belas artes: teatro, artes plásticas, literatura, cinema, música, dança -, a cultura é algo próprio dos talentosos ou dos que receberam formação específica. Aqui, não se valoriza o trabalho de criação, nem seu modo de inserção na sociedade e na história, mas a exposição dos resultados, isto é, a cultura como espetáculo, também passivamente recebido. Tornase lazer e entretenimento". Segundo Chaui, (Id., p. 8, grifos no original): "Para a esquerda, a cultura é a capacidade de decifrar as formas da produção social da memória e do esquecimento, das experiências, das ideias e dos valores, da produção das obras de pensamento e das obras de arte e, sobretudo, é a esperança racional de que dessas experiências e ideias, desses valores e obras surja um sentido libertário, com força para orientar novas práticas sociais e políticas das quais possa nascer outra sociedade". Nota-se, nesse sentido, a tendência de autores críticos em se contrapor à ideologia do "discurso competente" por um conceito de arte ou de cultura com referência o mais ampla possível. Paulo Freire, por exemplo, coloca que como, ao ser alfabetizado, o analfabeto "[d] escobriria que tanto ele, como o letrado, têm um ímpeto de criação e recriação. [...] Descobriria que tanto é cultura o boneco de barro feito pelos artistas, seus irmãos do povo, como cultura também é a obra de um grande escultor, de um grande pintor, de um grande místico, ou de um pensador. [...] Que cultura é a poesia dos poetas letrados de seu País, como também a poesia de seu cancioneiro popular. Que cultura é toda criação humana." FREIRE, Paulo. Educação como prática da liberdade. 8. ed. Rio de Janeiro: Paz e Terra, 1978. p. 109. 
pela pessoa, enquanto as desigualdades de comunicação no sistema artístico são fundantes para as posteriores visões de mundo que se produzirá de acordo com a arte que acople pessoa e sociedade.

4. Disparidades entre culturas, países ou "nações"

Apesar de se considerar a sociedade e os sistemas sociais funcionais como âmbitos comunicacionais operantes na dimensão espacial mundial, já sem um autofechamento das culturas nacionais sobre si mesmas, de forma territorialmente baseada e estatalmente dirigida, não se pode desconsiderar o peso que a diferenciação segmentária por países continua tendo como referência implícita ou explícita dos fluxos comunicacionais nos diversos sistemas. A estruturação dos países enquanto Estados nacionais obedece a uma construção semântica que buscou sobrevalorizar uma identidade comum em relação ao caráter multinacional de quase todos os territórios e povos estatalmente organizados. Também a segmentação por culturas - mais flexível e vaga - é inclusive reforçada pelos discursos sobre o multi, pluri, trans ou interculturalismo.

Chega-se a um ponto em que, afinal, podem ser traduzidas juridicamente como direitos humanos fundamentais tanto as pretensões de reconhecimento das manifestações da cultura nacional - altamente conformadoras de identidades pessoais e, portanto, jamais desprezíveis ${ }^{99}$ - quanto as afirmações contrafáticas de respeito aos multiculturalismo emergente nos países com recepção crescente de migrantes de diversas partes do mundo.

Assim é que a concepção de culturas, no plural, tem por referência a própria autorrepresentação de um dado grupo que se distingue por compartilhar certos conhecimentos e práticas simbólicas, formando assim uma comunidade cultural (cultura dos índios de certa tribo, cultura indígena, cultura urbana, cultura ocidental, cultura brasileira, etc.). Os limites de uma comunidade cultural são fluidos e há uma sobreposição incomensurável de comunidades culturais com relação às quais uma pessoa pode afirmar seu pertencimento simultâneo. Não necessariamente há consenso valorativo e finalístico no interior de uma comunidade cultural (como considerava o tradicional conceito de comunidade, contraposto ao de sociedade, de Tönnies), ${ }^{100}$ mas decerto há uma base

99 Grimm comenta que a "liberdade cultural" implica que "ninguém pode ser despojado no estrangeiro das formas de vida e dos traços característicos que se arraigaram em si. Por trás disso oculta-se, de uma parte, o temor à estrangeirização: já não caberá sentir-se em casa estando no próprio país; de outra, o temor ao imperialismo cultural: impõem-se novas formas de comportamento e valores que não são os próprios e que não seriam aceitos de modo voluntário". GRIMM, Dieter. Multiculturalidad y derechos fundamentales. In: GUTIÉRREZ GUTIÉRREZ, Ignacio (Ed.). Derecho constitucional para la sociedad multicultural. Madrid: Trotta, 2007. p. 53.

100 Sobre tal conceito, cf. LUHMANN, Niklas. La sociedad de la sociedad. cit., p. 846. 
de sentido compartilhada que facilita a comunicação (mesmo dissensual), condensa identidades individuais (como parcela da sociedade incorporada ao indivíduo na forma de habitus), ${ }^{101}$ constitui a própria autoidentidade da comunidade (descrita em uma observação de primeiro grau - por seus próprios participantes - como grupo, tribo, rede ou de qualquer outra forma) e se incorpora na hetero-observação que uma comunidade realiza quanto ao seu ambiente (outras comunidades culturais). ${ }^{102}$

Nas operações de auto e hetero-observação, a coexistência de múltiplas dicotomias culturais sobrepostas umas às outras (Ocidental/Oriental, moderno/tradicional, urbano/rural, central/periférico, Norte/Sul) e a simultânea localização do observador de um lado de cada uma delas (ou no ponto cego da diferença, quando tal diferença não se lhe aplica) não as faz deixarem de existir - se, em uma observação de primeiro grau, vêse sentido em aplicá-las conforme a situação, não há porque negar sua plausibilidade. $\mathrm{O}$ problema está na adequação descritiva de certa dicotomia e na absolutização de uma em detrimento das demais. Tal absolutização toma muitas vezes a forma de uma conjunção necessária de lados de diversas dicotomias a que se atribui um valor positivo - e.g., moderno, central, urbano - e, inversamente, de uma conjunção dos valores negativos (embora essa afirmação negativa, no sentido valorativo, também possa se expressar como um repúdio à própria diferenciação baseada em determinado par de positivo/negativo). Grande perigo descritivo reside na moralização das análises, que se resumem afinal ao código-diferença da moral (bom/mau ${ }^{103}$ ou consideração/desprezo) ${ }^{104}$ e transformam a evolução (mudança estrutural) em um dever-ser moral: progresso. ${ }^{105}$ Por outro lado, também pode subsistir a

101 Bourdieu conceitua habitus como "as disposições adquiridas, as maneiras duráveis de ser ou de fazer que se encarnam nos corpos [...]”. BOURDIEU, Pierre. Questões de sociologia. Tradução de Jeni Vaitsman. Rio de Janeiro: Marco Zero, 1983. p. 24.

102 Nesse sentido, o conceito de comunidade cultural aqui proposto pode distanciar-se das versões criticadas por Teubner e Fischer-Lescano: "Claro que isso requer forte autodisciplina para escapar de cantos da sereia: "choque de civilizações" ["clash of cultures"] (Samuel Huntingdon) nas relações internacionais; "Jihad vs. McWorld” (Benjamin Barber) na ciência política; "modernidades múltiplas” (Schmuel Eisenstadt) na sociologia; "unicidade de culturas legais" (Pierre Legrand) na ciência jurídica. Todas essas formas insinuam que na atual sociedade global diferentes culturas regionais, hermeticamente apartadas uma das outras, colidem. Por mais influentes que tenham se tornado tais conceitos de conflito cultural entre sociedades modernas e tradicionais, são questionáveis suas suposições de culturas como totalidades ou 'compacidades', unidades exclusivas 'tout court', que tem que lutar para assegurar suas fronteiras". TEUBNER, Gunther; FISCHER-LESCANO, Andreas. Cannibalizing epistemes: will modern law protect traditional cultural expressions? cit., p. 23.

103 LUHMANN, Niklas. La sociedad de la sociedad. cit., p. 289.

104 NEVES, Marcelo. Entre Têmis e Leviatã: uma relação difícil: o Estado Democrático de Direito a partir e além de Luhmann e Habermas. cit., p. 50.

105 LUHMANN, Niklas. Sociologia do direito I. Tradução de Gustavo Bayer. Rio de Janeiro: Tempo Brasileiro, 1983. p. 142, 170-177, 193; ___ ; ___ Sociologia do direito II. Tradução de Gustavo Bayer. Rio de Janeiro: Tempo Brasileiro, 1985. p. 118, 177; ___. Law as a social system. Tradução de Klaus Ziegert. London: Oxford University, 2004. p. 470-1;____ La sociedad de la sociedad. cit., esp. p. 332, 337, 382 , 438, 708 e 796. Cf. NEVES, Marcelo. Entre Têmis e Leviatã: uma relação difícil: o Estado Democrático de 
ideia de progresso em uma teoria como a das "múltiplas modernidades" (Eisenstadt), ${ }^{106}$ que concebe vários caminhos de ser moderno, mas localiza a origem da modernidade na Europa. Já autores como Sen podem negar tal origem e identificar fontes orientais da modernidade, ${ }^{107}$ mas ao mesmo adotar uma visão de progresso ainda predominantemente unilinear ${ }^{108}$ - não como simples autodesenvolvimento das estruturas de certa "comunidade cultural" em contato com outras, mas como um caminho de modernização, como na evolução nas espécies biológicas. ${ }^{109}$

Adotando-se o enfoque construtivista luhmanniano, entende-se que os sistemas que operam por meio do sentido - sistemas sociais e psíquicos, que se acoplam, principalmente pela linguagem, para possibilitar a comunicação - necessitam construir a realidade internamente a si mesmos com base em conceitos, que são sempre distinções (por mais que apenas se explicite um lado, deixando o outro tácito). ${ }^{110}$ Talvez o que haja de fato é uma hipertrofia das dicotomias, que ultrapassa sua capacidade descritiva - nem tudo pode ser explicado pela contraposição Ocidente/Oriente. ${ }^{111}$ Por outro lado, decerto elas carregam sentidos (estruturam ideias gerais, abstratas) e não são meras construções para elidir a verdade; embora, como todo conceito/distinção, sejam construções de sentido

Direito a partir e além de Luhmann e Habermas. cit., p. 1-18.

106 EISENSTADT, Shmuel N. Multiple modernities. In: . (Ed.). Multiple modernities. New Brumswick: Transaction, 2000.

107 SEN, Amartya. Desenvolvimento como liberdade. Tradução de Laura Teixeira Motta. São Paulo: Companhia das Letras, 2000. p. 265-283.

108 Id., p. 275-276: "No contexto das disparidades econômicas, a resposta apropriada tem de incluir esforços conjuntos para tornar a forma da globalização menos destrutiva para o emprego e o modo de vida tradicional e para ocasionar uma transição gradual. A fim de suavizar o processo de transição, é preciso que haja também oportunidades para um novo preparo profissional e a aquisição de novas qualificações (para as pessoas que, de outro modo, seriam alijadas do mercado de trabalho), juntamente com a provisão de redes de segurança social (na forma de seguridade social e outras disposições de apoio) para aqueles que têm seus interesses prejudicados - ao menos no curto prazo - pelas mudanças globalizantes".

109 Id., p. 276-277: "No caso da cultura, porém, as tradições perdidas podem fazer muita falta. A extinção de antigos modos de vida pode causar angústia e um profundo senso de perda. É um pouco como a extinção de espécies animais mais antigas. A eliminação de velhas espécies em favor de espécies 'mais aptas' com condições 'melhores' para sobreviver e multiplicar-se pode ser lamentada, e o fato de as novas espécies serem 'melhores' no sistema de comparação darwiniano não necessariamente será visto como suficientemente consolador".

110 LUHMANN, Niklas. La sociedad de la sociedad. cit., p. 31.

111 COSTA, Sérgio. Dois Atlânticos: teoria social, anti-racismo, cosmopolitismo. Belo Horizonte: Ed. UFMG, 2006, esp. p. 118-120. Costa (Id., p. 119, grifos no original) comenta: "A inspiração que anima Said - e, como se mostra mais adiante, boa parte dos autores pós-coloniais - é a crítica foucaultiana à 'episteme' das ciências humanas [...]. Trata-se de mostrar que a produção de conhecimento atende a um princípio circular e auto-referenciado, de sorte que 'novos' conhecimentos construídos sobre uma base de representação determinada reafirmam, ad infinitum, as premissas inscritas nesse sistema de representações. O orientalismo caracteriza, assim, um modo estabelecido e institucionalizado de produção de representações sobre uma determinada região do mundo, o qual se alimenta, se confirma e se atualiza por meio das próprias imagens e dos conhecimentos que (re)cria". 
simplificadoras, aproximando-se de tipos ideais, ${ }^{112}$ o que é preciso sempre pressupor quando se lhes aplica. É importante se ter em vista que múltiplas construções são possíveis e que a sobreposição de múltiplas dicotomias pode elidir os pontos cegos de cada uma, ${ }^{113}$ fundando a comparação e o diálogo entre as culturas, ${ }^{114}$ bem como aclarando a "diversidade e variedade dentro de uma tradição [...]". ${ }^{115}$

\subsection{A referência nacional}

Retomando o conceito de comunidade cultural (definida por auto e heteroobservações, portanto conceitos, dicotomias, construções de uma comunidade sobre si mesma e as demais comunidades), cabe analisar o conceito de nação. Nação, em sentido estrito (na referência a Estados nacionais), pode ser entendida como uma base comum de sentido presente nas comunicações da população de um dado espaço definido como o território de um Estado - o que há de comum entre as culturas das várias localidades e regiões de um país, ao lado de uma construção simbólica e identitária reforçada politicamente para a criação de um sentido de unidade e identificação. Se se entender nação, em sentido amplo, como qualquer grupo de sentidos e pessoas historicamente vinculados (mantendo-se a vinculação entre cultura e história presente no conceito de nação), todo Estado será plurinacional, com diferenças de grau, sempre temporalizadas - os fenômenos migratórios fundem e confundem condensações de sentido desenvolvidas em dado espaço, mas que são transferidas para outros, e a memória individual (dos pensamentos) e dos sistemas sociais (das comunicações) regula a nitidez de uma origem nacional, em sentido amplo ou estrito (ambos os sentidos acabam se fundindo e se confundindo). Quando se faz referência a um Estado plurinacional, pode-se antes entender que naquele país (região da sociedade mundial segmentada em referência principalmente ao sistema político, cujo centro é o Estado) falta uma cultura nacional (nação em sentido estrito, com uma referência política reforçada) que coexista com comunicabilidade - i.e., que seja uma referência de sentido usual - ao lado das diversas culturas nacionais em sentido amplos (grupos que se identificam historicamente principalmente no plano simbólico).

$\mathrm{O}$ próprio conceito de nação ${ }^{116}$ já se apresenta como uma noção em crise, como um obstáculo epistemológico, ${ }^{117}$ "pertence àquele punhado de semânticas

\footnotetext{
$112 \quad$ Id., p. 129-131.

113 LUHMANN, Niklas. La sociedad de la sociedad. cit., p. 699.

114 Cf. SANTOS, Boaventura de Sousa. Por uma concepção multicultural de direitos humanos. cit.; Towards a multicultural conception of human rights. cit.

115 SEN, Amartya. Desenvolvimento como liberdade. cit., p. 274 (grifo no original).

116 Cf. FOUCAULT, Michel. Em defesa da sociedade: curso no Collège de France (1975-1976). Tradução de Maria Ermantina Galvão. São Paulo: Martins Fontes, 2002. p. 257-284.

117 LUHMANN, Niklas. La sociedad de la sociedad. cit., p. 836. Cf. LUHMANN, Niklas. Law as a social
} 
transitórias que puderam causar fascinação por um tempo suportável sem mencionar a que sistema social se referiam". ${ }^{118}$ A própria análise sociológica exige um descentramento de sua referência nacional, procurando entender as inter-relações complexas no plano global, inclusive aquelas sem uma base de referência nacional. ${ }^{119}$

O conceito de nação é construído como uma "semântica de contenção" que reage à diferenciação funcional. ${ }^{120}$ A segmentação representada por Estados soberanos sobre seus territórios ganha apenas com a Revolução Francesa sua representação pela semântica da "nação", com o que se pretende assinalar "a abolição das tradicionais diferenças sociais"; esse conceito se difunde para outros contextos, trazendo sua carga comparatística a comunicações culturais e políticas que pretendem realçar identidades territorialmente delimitadas (concebidas por um apelo a certa narrativa histórica) e as relações entre estas.

Seguindo a distinção de Ferdinand Tönnies ${ }^{121}$ entre sociedade e comunidade, à sociedade funcionalmente diferenciada opõe-se a nação enquanto comunidade cultural imaginada que partilha um passado, um presente e um futuro, uma história, um idioma e uma finalidade comum. ${ }^{122}$ Para Luhmann, a construção da nacionalidade obedece a uma necessidade de identidade que se torna presente quando as tradicionais hierarquizações e estratificações são submetidas a uma crise pelo advento da diferenciação funcional; já que a inclusão em cada sistema parcial não permite mais uma identidade suficiente, o conceito de nação busca oferecê-la, vinculando a nacionalidade ao conceito de povo, agora restrito à política (e ao direito) e ampliado da referência apenas aos estratos baixos da população. O povo exige tratamento igual para os seus membros e uma proteção estatal do que é tipicamente nacional diante da universalização proporcionada pela mundialização da economia desde o século XV e pela ampliação das "visões de mundo" religiosas ou-não, que passaram a ter maior consciência uma das outras. ${ }^{123}$

Com a globalização, não se arrefeceram totalmente as identidades nacionais (referidas ao pertencimento a um determinado Estado), muitas vezes reativadas em reação à

system. cit., p. 448.

118 LUHMANN, Niklas. La sociedad de la sociedad. cit., p. 836.

119 Sobre tal ideia de descentramento sociológico, cf. COSTA, Sérgio. Dois Atlânticos: teoria social, antiracismo, cosmopolitismo. cit.; COSTA, Sérgio; DOMINGUES, José Maurício; KNÖBL, Wolfgang; SILVA, Josué Pereira da. How plural is modernity? Zentrum und Peripherie, München, v. 3, 2006; SPOHN, Willfried. Multiple, entangled, fragmented and other modernities. Reflections on comparative sociological research on Europe, North and Latin America. Zentrum und Peripherie, München, v. 3, 2006.

120 LUHMANN, Niklas. La sociedad de la sociedad. cit., p. 828.

121 A distinção de Tönnies "afirma uma diferença histórica entre estruturas tradicionais e modernas da sociedade cuja confusão atual se torna objeto de análise” (Id., p. 846). Cf. TÖNNIES, Ferdinand. Community and civil society. Cambridge: Cambridge University Press, 2001.

122 LUHMANN, Niklas. La sociedad de la sociedad. cit., p. 830.

123 Id., p. 833. 
imigração nos países centrais; porém houve, de fato, como nota Eisenstadt, ${ }^{124}$ um processo paralelo de reforço de identidades étnicas, locais, regionais e transnacionais. Há, antes, uma "erosão seletiva" 125 do Estado, das referências nacionais, principalmente em relação aos fluxos econômicos (e a outros a estes relacionados, como os da técnica, da ciência e da comunicação de massa) comandados por grandes organizações. Em outros sistemas e para boa parte das organizações e pessoas sem o domínio destes fluxos, a referência nacional desgasta-se menos, e suas atitudes e estratégias tendem a ser predominantemente reativas a uma perda da nação como referência, limite e distinção.

\subsection{Globalização, direitos humanos e cultura}

Sobre o conceito de globalização reina enorme controvérsia no campo das diversas ciências sociais, tanto no que se refere a seu conteúdo, quanto no que diz com sua inserção temporal e relevância histórica. ${ }^{126}$ Em uma sociedade mundial totalmente adaptada à diferenciação funcional, nenhum sistema pode colocar-se como centro regulador da vida social. ${ }^{127}$ Evidencia-se, porém, que a diferenciação funcional não é uma forma dominantemente presente na grande maioria dos espaços da sociedade mundial, seja essa ausência intencionada pelas populações desses territórios (por peculiaridades culturais); ${ }^{128}$ seja pela posição subalterna destas no plano das grandes disparidades de riquezas entre os países, inegável mesmo que se problematize o esquema centro/periferia; seja pelas disparidades econômicas internas, entre pessoas e regiões, verificadas quando se analisa segmentariamente país por país. Justamente a distância entre essa realidade de diferenciações intersistêmicas precárias e a teoria de uma sociedade mundial moderna funcionalmente diferenciada é ressaltada por alguns como exemplo do caráter normativo da teoria luhmanniana, embora esta afirme que pretende elidir quaisquer prescrições. ${ }^{129}$

124 EISENSTADT, Shmuel N. Multiple modernities. cit., p. 17.

125 SANTOS, Boaventura de Sousa. Por uma concepção multicultural de direitos humanos. cit., p. 431.

126 Cf. PIETERSE, Jan Nederveen. Globalization \& culture: global mélange. 2. ed. Lanham: Rowan \& Littlefield, 2009. p. 7-23; ZOLO, Danilo. Globalização: um mapa dos problemas. Tradução de Anderson Vichinkeski Teixeira. Florianópolis: Conceito, 2010.

127 LUHMANN, Niklas. La sociedad de la sociedad. cit., p. 636-637. Cf. HABERMAS, Jürgen. O discurso filosófico da modernidade. Tradução de Luiz Sérgio Repa e Rodnei Nascimento. São Paulo: Martins Fontes, 2000. p. 518.

128 Tal é a hipótese problemática aventada por LUHMANN, Niklas. La sociedad de la sociedad. cit., p. 639.

129 FISCHER-LESCANO, Andreas. A teoria crítica dos sistemas da Escola de Frankfurt. cit., p. 165. Cf. HABERMAS, Jürgen. $O$ discurso filosófico da modernidade. cit., p. 511-534. 
Diversas análises têm diagnosticado que a globalização aumenta a exclusão social dentro dos países, ${ }^{130}$ inclusive com tendências à "periferização do centro". ${ }^{131} \mathrm{Em}$ referência às pessoas, a exclusão de um sistema tende a produzir a exclusão de outros, em uma reação em cadeia que acaba produzindo um impacto desdiferenciante mesmo nos países ou regiões diferenciados. Já que os direitos fundamentais, notadamente, têm "âmbitos de normas mais complexos e integral ou parcialmente não-gerados pelo direito [...]", ${ }^{132}$ o enfraquecimento dos pressupostos de sua realização mesmo nos países centrais há que ser notado quando se analisa a relação entre globalização e direitos humanos.

Embora não se coloque como centro da sociedade mundial, o sistema econômico (ao lado do educacional, segundo Luhmann) ${ }^{133}$ é, em regra, o primeiro a desencadear a exclusão cíclica das pessoas em relação aos demais sistemas funcionais. A economia, ao lado da ciência e da técnica, é o motor estrutural da globalização; ${ }^{134}$ notadamente, hoje, se se observar o problema dos "meios de comunicação específicos de um sistema social expansivo", em analogia ao poder do Estado, "[e]conomia e tecnologia são os óbvios novos candidatos". ${ }^{135}$

Se inicialmente a politização das demais esferas é que deu ensejo à construção liberal dos direitos fundamentais, a experiência dos últimos séculos mostrou que a diferenciação social também pode ser turbada pelo expansionismo do medium "dinheiro", pela colonização econômica de outros subsistemas sociais. O "círculo autodestrutivo"136 da diferenciação funcional, que implica a exclusão em cadeia dos sistemas (notadamente a partir da economia e da educação), ${ }^{137}$ repete-se com relação aos vários sistemas com forte tendência expansionista: "diferenciação [do sistema funcional] [...] - autonomia - perda de limites inerentes - tendências expansionistas - politização [economicização, etc.] dos outros setores - risco de desdiferenciação". ${ }^{138}$

130 Cf., entre outros, MÜLLER, Friedrich. Que grau de exclusão social ainda pode ser tolerado por um sistema democrático. In: PIOVESAN, Flávia (Coord.). Direitos humanos, globalização econômica e integração regional: desafios do direito constitucional internacional. São Paulo: Max Limonad, 2002.

131 NEVES, Marcelo. Entre Têmis e Leviatã: uma relação difícil: o Estado Democrático de Direito a partir e além de Luhmann e Habermas. cit., p. 271-274.

132 MÜLLER, Friedrich. Métodos de trabalho do direito constitucional. cit., p. 29.

133 LUHMANN, Niklas. La sociedad de la sociedad. cit., p. 613-614.

134 NEVES, Marcelo. Transconstitucionalismo. São Paulo: Martins Fontes, 2009. p. 27-32.

135 GRABER, Christoph Beat; TEUBNER, Gunther. Art and money: constitutional rights in the private sphere? cit., p. 70.

136 Id., p. 65.

137 LUHMANN, Niklas. La sociedad de la sociedad. cit., p. 613-614.

138 GRABER, Christoph Beat; TEUBNER, Gunther. Art and money: constitutional rights in the private sphere? cit., p. 65. Quanto ao sistema econômico, Luhmann (LUHMANN, Niklas. La sociedad de la sociedad. cit., p. 574) nota que "o conceito de mercado se desliga da designação de certos lugares liberados para as transações e se converte em forma conceitual para vir a designar a lógica própria daquelas transações que não dependem de nenhumas outras características sociais". 
Se a desdiferenciação hoje é principalmente um problema relacionado ao expansionismo da economia, no plano estrutural, cabe notar suas consequências no plano semântico. Nesse aspecto, a liderança do processo de globalização é dada ao sistema dos meios de comunicação de massa. ${ }^{139}$ Em grande medida, a própria semântica da globalização é uma produção desse sistema: conforme nota Luhmann, ${ }^{140}$ no final do século XX “observa-se uma crescente discrepância entre semântica e realidade”, vinculada ao fato de que "as possibilidades de autodescrição da sociedade moderna" seguem "leis próprias dos meios de massas”.

A semântica da globalização produzida pelos meios de comunicação de massa ressalta ainda mais, latente ou explicitamente, a redução e a identificação do "mundo sem fronteiras" à economia capitalista sem fronteiras. As "particularidades muito discutidas das modernas estruturas do tempo, como dominação do esquema passado/ futuro, uniformização do tempo mundial, aceleração, extensão dos eventos sincrônicos aos assincrônicos"141 tomam por base o funcionamento de sistemas funcionais como a economia e os meios de comunicação de massa (estes, por excelência geradores e processadores de um excesso de informações e "irritações" ${ }^{142}$ ), não podendo responder por uma caracterização global da sociedade, uma vez admitida a igualdade entre os sistemas funcionais desiguais, igualdade esta que caracteriza a sociedade mundial moderna, segundo a análise luhmanniana.

A crítica de Friese e Wagner ${ }^{143}$ é sintética e precisa ao aludir às visões de mundo construídas na linha da maioria das vertentes sociológicas autointituladas pósmodernas (com foco nas identidades, hibridismos, glocalidades e multiculturalismos), bem como pelas teorias ou ideologias da globalização, ambas (ou uma só?) assumindo, quase sempre com um exagero retórico e sem bases empíricas suficientes, "que não há mais vínculos estáveis, que tudo é contingente e fluído".

Não cabe, pois, perder de vista as continuidades estruturais e semânticas existentes, senão que (pre)dominantes para a maioria das pessoas na atualidade. Em primeiro lugar, em relação a parcela não desprezível das pessoas que habitam o mundo contemporâneo, as referências nacionais e locais permanecem com inegável força na constituição de suas identidades, perspectivas e expectativas de vida, sendo que a “desterritorialização" tende a atingir com menos impacto as camadas médias da sociedade,

139 NEVES, Marcelo. Transconstitucionalismo. cit., p. 27-32.

140 LUHMANN, Niklas. La sociedad de la sociedad. cit., p. 868-869.

141 LUHMANN, Niklas. A realidade dos meios de comunicação. cit., p. 45.

142 Id., p. 47.

143 FRIESE, Heidrun; WAGNER, Peter. Not all that is solid melts into air: modernity and contingence. In: FEATHERSTONE, Mike; LASH, Scott (Eds.). Spaces of culture: city, nation, world. London: Sage, 1999. p. 113. 
em relação às excluídas ou subincluídas (política ou, via de regra, economicamente), ou às sobreincluídas e bem incluídas (com razoável "comunicabilidade" no sistema econômico, técnico, científico, artístico ou dos meios de comunicação de massa). Também não se pode negar que a semântica das diferenças de classe, em uma observação de primeira ordem ao menos, é altamente verossímil diante da negação, à maior parcela da população mundial, do acesso às prestações da maioria dos sistemas sociais, desencadeada por uma exclusão ou subinclusão primordial dos sistemas econômico e educacional, mesmos sistemas que promovem camadas com maior "comunicabilidade", acesso às prestações e poder de decisão nos diversos sistemas - posição que, quando associada a ingerências personalistas e redes de relacionamento, parentesco e afinidade (capital social), tende a reproduzir a sobreinclusão.

O sistema dos meios de comunicação de massa está, em suas operações, fortemente irritado por outros sistemas, como a economia e a política, bem como gera uma abundância de irritações em direção a esses sistemas. ${ }^{144}$ De fato, embora sejam sistemas autônomos a economia e os meios de comunicação de massa, as organizações responsáveis pela difusão da informação não estão estritamente vinculadas a este sistema, mas também funcionam como "indústria cultural”, já então dentro também do sistema econômico. Operando fortemente com base em referências globais e vinculado organizacionalmente à economia (que também se reproduz fortemente no plano mundial), a produção da realidade pelo sistema dos meios de comunicação, enquanto construção da realidade mais difundida pela sociedade e com as limitações intrínsecas a seu modus operandi, tende a reduzir a importância das culturas locais no dia a dia das pessoas (que

144 Embora se possa postular a existência de um acoplamento estrutural entre sistema econômico e sistema dos meios de comunicação de massa por meio da publicidade, Luhmann (LUHMANN, Niklas. A realidade dos meios de comunicação. cit., p. 90-91, grifos no original) entende que "[e]xatamente na relação entre economia e publicidade encontram-se assim bons argumentos para uma diferenciação crescente dos sistemas com uma redução dos acoplamentos estruturais. [...] O sucesso da publicidade não está somente no econômico, no sucesso de vendas. O sistema dos meios de comunicação tem, também aqui, uma função própria e esta deve-se localizar na estabilização da relação entre redundância e variedade na cultura cotidiana". Em contraste com sua noção de acoplamento estrutural como relação horizontal ou ortogonal de mútua limitação entre os sistemas (acoplados), Luhmann (Id., p. 115) estranhamente considera: "No setor da publicidade, portanto, tanto a economia é dependente do sistema dos meios de comunicação como este daquela; e não se constata, como no caso típico dos acoplamentos estruturais, nenhuma assimetria lógicoefetiva, nenhuma hierarquia". No setor de notícias e reportagens, "há claros acoplamentos estruturais entre o sistema dos meios de comunicação e o sistema político A política lucra com as 'menções' nos meios de comunicação e se vê ao mesmo tempo irritada com elas [...]. Os comunicados nos meios de comunicação exigem em geral uma reação no sistema político, que reaparece regularmente como comentário nesses mesmos meios. Em ampla medida, portanto, as mesmas comunicações têm ao mesmo tempo relevância medial e política. Mas isso vale exclusivamente para acontecimentos isolados e somente ad hoc. Pois o tratamento posterior segue, no sistema político, especialmente sob as condições da democracia e quando a oposição estrutura-se na forma de partidos, caminhos totalmente diferentes do que nos meios de comunicação, onde há uma espécie de história em capítulos” (Id., p. 117, grifos no original). 
vivem "localmente", em sua maioria). Embora justamente a presença de uma "cultura global" engendrada pelo sistema econômico e da comunicação de massa ${ }^{145}$ reforce o reconhecimento de culturas locais, estas somente podem ter algum espaço de difusão, enquanto reconstruídas pelo sistema dos meios de comunicação como novidade e exotismo capaz de integrar-se em uma cultura mundial "transcultural", "global". Também a relação entre várias culturas, quando o discurso do multiculturalismo penetra os meios de comunicação e é por estes reproduzido, torna-se extremamente simplificada: podese manter uma "atitude básica conservadora em relação à própria cultura e uma relação apenas turística com as demais". ${ }^{146}$

No plano da cultura, portanto, a arte é reelaborada, senão por um acoplamento, por uma mediação organizacional entre os sistemas da economia e dos meios de comunicação. Enquanto Adorno e Horkheimer ${ }^{147}$ visualizavam uma completa instrumentalização da arte pela economia, característica da esfera dos meios de comunicação de massa, ${ }^{148}$ Graber e Teubner ${ }^{149}$ visualizam na "distinção entre código e programa" e na "distinção entre acoplamento frouxo e estreito" ferramentas conceituais úteis para sustentar na atualidade não a total economicização da arte - codificação da arte não mais pela beleza, mas pelo dinheiro -, porém ameaças à sua autonomia sistêmica que advêm dos "caminhos concretos em que essas interdependências [entre arte e economia] são institucionalizadas".

Para Luhmann, ${ }^{150}$ "os efeitos de diversos sistemas funcionais combinam-se, amplificam-se e bloqueiam-se, em razão de condições que só se apresentam regionalmente e que, por conseguinte, produzem modelos muito distintos". Dada a vinculação reforçada pela globalização - pelos sistemas da economia e dos meios de comunicação de massa -

145 Cf. LIPOVETSKY, Gilles; SERROY, Jean. A cultura-mundo: resposta a uma sociedade desorientada. Tradução de Maria Lúcia Machado. São Paulo: Companhia das Letras, 2011.

146 LUHMANN, Niklas. A realidade dos meios de comunicação. cit., p. 143.

147 ADORNO, Theodor W; HORKHEIMER, Max. Dialética do esclarecimento: fragmentos filosóficos. Tradução de Guido Antonio de Almeida. Rio de Janeiro: Zahar, 1985, esp. p. 99-138.

148 Arendt (ARENDT, Hannah. Entre o passado e o futuro. Tradução de Mauro W. Barbosa. 6. ed. São Paulo: Perspectiva, 2009. p. 257) observa: "Talvez a principal diferença entre a sociedade e a sociedade de massas esteja em que a sociedade sentia necessidade de cultura, valorizava e desvalorizava objetos culturais ao transformá-los em mercadorias e usava e abusava deles em proveito de seus fins mesquinhos, porém não os 'consumia'. Mesmo em suas formas mais gastas esses objetos permaneciam sendo objetos e retinham um certo caráter objetivo; desintegravam-se até se parecerem a um montão de pedregulhos, mas não desapareciam. A sociedade de massas, ao contrário, não precisa de cultura, mas de diversão, e os produtos oferecidos pela indústria de diversões são com efeito consumidos pela sociedade exatamente como quaisquer outros bens de consumo".

149 GRABER, Christoph Beat; TEUBNER, Gunther. Art and money: constitutional rights in the private sphere? cit., p. 71.

150 LUHMANN, Niklas. La sociedad de la sociedad. cit., p. 640. 
entre cultura e economia, as disparidades econômicas entre países reforçam ainda mais a disparidade da difusão das respectivas culturas.

Mesmo um diagnóstico de que, “especialmente após a Segunda Guerra Mundial", os "desenvolvimentos em sociedades modernizantes refutou as hegemônicas e homogeneizadoras as suposições deste programa ocidental de modernidade"151 não pode negar que a globalização se expressa, "na arena cultural", com "a hegemônica expansão, pela media dominante em muitos países, do que são, aparentemente uniformes, programas culturais e visões ocidentais, sobretudo americanos". ${ }^{152}$ De fato, as culturais mais comunicáveis apresentam-se já não mais em referências claras a suas origens nacionais, mas como culturas globais, a impor-se muitas vezes normativamente, guiadas pelo sistema econômico e reproduzindo as diferenças de comunicabilidade (de pessoas, países, culturas) presentes nesse sistema. A tendência da globalização é, portanto, a de ir contra o postulado de que "os optima globais e regionais divergem marcadamente [...]". ${ }^{153}$

\subsection{Diferenças entre culturas e a(s) cultura(s) da(s) modernidade(s)}

A ideia de modernidade tem origem no próprio surgimento da cultura como plano de reflexão da sociedade sobre si mesma, conceituação esta só oferecida pela Europa do século XVIII, (auto)descrita como moderna e centro da cultura ou berço da civilização. ${ }^{154}$ Ao lado de cultura, modernidade é um dos termos mais problemáticos da comunicação atual, já que sofreu mutações profundas ao longo dos séculos, notadamente do último. Cabe, portanto, problematizar a semântica da sociedade que se concebe historicamente como moderna, historicizando a historiografia, já que "[a] história contém sua própria descrição [...] [que] varia com o curso da história". ${ }^{155}$

A semântica da modernidade se constrói por uma rejeição ao passado (prémoderno, estamental) e "encaminha [...] à necessidade crescente de autossignificação da modernidade - a qual, por sua vez, leva à impossibilidade de conciliação, quer dizer, às controvérsias ideológicas". ${ }^{156}$ A própria fortificação da necessidade de autovaloração da sociedade moderna está relacionada à multiplicação exponencial da quantidade de informação difundida rápida, ampla e redundantemente na sociedade pelos meios de comunicação, informações estas que precisam ser subsumidas a um esquema geral de

\footnotetext{
151 EISENSTADT, Shmuel N. Multiple modernities. cit., p. 1.

152 Id., p. 16.

153 LUHMANN, Niklas. La sociedad de la sociedad. cit., p. 640 (grifo no original).

154 Id., p. 699.

155 Id., p. 849.

156 Id., p. 850.
} 
interpretação, a um “julgamento global”. ${ }^{157}$ Pelos meios de comunicação de massa, por exemplo, os esquemas novo/velho, moderno/pré-moderno ou afins são reproduzidos. Esses esquemas guiam a desvalorização do passado, que somente pode sobreviver seletiva e simbolicamente (artística ou culturalmente) se dele se extraírem suficientes possibilidades de novas informações, preços, usos, interpretações. ${ }^{158}$ Por outro lado, mesmo as novidades são normalizadas ${ }^{159}$ e têm que ser reapresentadas redundantemente de modo a mobilizar atenção e produzir alguma irritação.

Sob a ótica de Luhmann, ${ }^{160}$ a sociedade moderna é autossignificada pelo thélos da emancipação e autorrealização individual, pelo ideário da equalização das classes por meio da distribuição dos excedentes econômicos e pela oposição à sociedade hierárquica estamental. Seu desenho se completa com a constitucionalização do sistema político e com a "liberação dos indivíduos para conduzirem sua própria vida". Essa semântica entra em crise no final do século XX com as dúvidas levantadas pelo fim do socialismo real soviético e pela "modernização" dos "países em desenvolvimento", política que buscava implementar regionalmente (nacionalmente) uma política e uma economia liberais (democracia e capitalismo), com liberdades juridicamente garantidas que possibilitassem a autonomia funcional dos sistemas e impedissem sua mútua "corrupção". A semântica de modernização "quase unilateral até agora vigente" é confrontada, seja nas regiões há muito modernas, seja nas modernidades "tardias", com questões que se desenham nas relações entre os sistemas funcionais e na insuficiência de seus mecanismos de heteroobservação, questões estas tais como:

É possível todavia um controle constitucional do desenvolvimento até o Estado de bem estar com os instrumentos clássicos da dogmática jurídica? E se não, como se pode evitar que a Suprema Corte de Justiça continuamente intervenha na política de uma maneira que não se pode legitimar democraticamente? Como pode a economia ou as administrações públicas financiadas pela economia procurar postos de trabalho que correspondam ao nível de adestramento que prepara o sistema educativo? E quais são as consequências políticas quando a crescente classe média acadêmica já não se conforma tão só com sua formação sem que a veja refletida em poder e renda? ${ }^{161}$

157 LUHMANN, Niklas. A realidade dos meios de comunicação. cit., p. 45-46.

158 Id., p. 46-47.

159 Id., p. 47.

160 LUHMANN, Niklas. La sociedad de la sociedad. cit., p. 857-862.

161 Id., p. 861-862. 
Uma das respostas gerais a esses questionamentos é a de que, como normatividade, ideário e projeto, a modernidade está inconclusa; para Luhmann, ${ }^{162}$ a modernidade em suas instituições reais permanece fundamentalmente igual, não sendo clara uma ruptura das formas de organização da educação, da economia e da política, por exemplo, que pudesse indicar a chegada da pós-modernidade. ${ }^{163}$ Ao procurar romper com a normatividade presente na tradição sociológica - portadora de ideais iluministas como a emancipação, a racionalidade, a igualdade e a liberdade -, colocando em xeque o potencial explicativo de tais orientações, o próprio Luhmann ${ }^{164}$ acaba admitindo que sua descrição sociológica da sociedade moderna não pode ser vista como inferior ou superior, mas simplesmente como "outra" - o que não o leva a invalidar sua avaliação de uma teoria estática da modernidade fundada na racionalização e na realização dos direitos humanos, ao constatar a irrealização dessa sociedade sonhada. Diante desse diagnóstico, Luhmann não concebe uma crise que já traga em si o advento da pós-modernidade.

Luhmann ${ }^{165}$ rejeita a linearidade simplista de uma evolução medida pela diferença antes/depois, sem maiores ponderações quanto à diversidade de critérios nas dimensões objetual e social da sociedade. Tem-se, pois, que considerar como a sociedade constrói em seu interior as diferenças sistema/entorno (inclusive construindo operacionalmente segmentações por país, com base étnica, histórica, cultural, etc.) e como

162 Id., p. 904-905.

163 Luhmann (Id., p. 862-868, 896-897) critica a descrição sociológica da sociedade por "palavras-chave", fórmulas "espetaculares" e "propagandísticas" ou por características de um sistema funcional supostas "como algo decisivo, dominante, determinante da forma" da sociedade - tais como capitalismo (economia), sociedade industrial ou pós-industrial (economia), sociedade do espetáculo (meios de comunicação de massa), sociedades de massa (política e meios de comunicação), sociedade da tecnociência (ciência, técnica e economia) ou do conhecimento (educação, técnica, economia). Mais recentemente, as fórmulas pouco nítidas da "sociedade da informação" (ou do conhecimento) ou da "sociedade de risco" focam-se em aspectos da comunicação e tomam "como representativos alguns fenômenos particulares" (Id, p. 863), obedecendo também à necessidade de simplificação da descrição da sociedade para a sociedade (redução da complexidade) e à demanda por enfatizar o historicamente novo. Em regra, refere-se ao surgimento da informática (computador e internet) e à consequente multiplicação da informação, que eleva a complexidade tecnológica e amplia a insegurança: "As notícias produzem e reproduzem inseguranças em relação ao futuro - contra todo um continuísmo do mundo conhecido, obtido com base na percepção cotidiana" (LUHMANN, Niklas. A realidade dos meios de comunicação. cit., p. 69). Luhmann (LUHMANN, Niklas. La sociedad de la sociedad. cit., p. 864) relê tais descrições segundo sua própria teoria, identificando a importância da diferenciação funcional como condição da informação e do risco. Prossegue afirmando que, se essa informação abundante não é sempre dada a conhecer e compreendida, consiste, na maioria das vezes, em informação potencial. Questiona ainda a implicação lógica de que, na sociedade da informação, este componente da comunicação (informação) teria mais importância em relação ao componente mensagem ou dar a conhecer (em que está envolvido o aspecto performativo da comunicação) e em relação ao componente compreensão, do que decorreria a menor relevância "do status e dos estratos sociais" e a maior demanda pela novidade da informação, que se torna de curta vida útil, entretanto.

Id., p. 904, 906.

165 Id., p. 325-469, esp. p. 900-901. 
trabalha o processo de comunicação, possibilitando diferentes compreensões segundo uma mesma informação tornada disponível.

Luhmann ${ }^{166}$ nota que há uma crítica genérica que hoje se dirige à simples contraposição entre tradição e modernidade, entre comunidade (fechada e voltada para o passado) e sociedade (aberta e voltada para o futuro), distinções estas que se refletiram fortemente nas teorias do "desenvolvimento" e da "modernização". Concorda com este diagnóstico a teoria das "modernidades múltiplas" ou "múltiplas modernidades" (multiple modernities), de Shmuel Eisenstadt, que rejeita "as visões otimistas da modernidade como progresso inevitável", identificando antes "cristalizações da modernidade" com base em "conflito interno e confrontação". ${ }^{167}$ Tal conceito foi expressamente desenhado em contraposição às " "clássicas' teorias [inspiradas por Talcott Parsons] ${ }^{168}$ da modernização e da convergência das sociedades industriais, prevalentes nos anos 1950, e também contra as clássicas análises sociológicas de Marx, Durkheim e (em grande medida) até de Weber $[\ldots] " .169$

Contra a medida do desenvolvimento de uma sociedade por instituições típicas de outra, assumidas como parâmetro normativo de modernidade (como a política democrática e a economia capitalista liberais dos Estados Unidos ou da Europa Ocidental) é que se sustentam críticas à descrição/prescrição de convergência na evolução, no desenvolvimento ou na modernização dos países. ${ }^{170}$ Descentrando a noção de modernidade e pluralizando-a de forma a apreender a complexidade da sociedade moderna, "[a] ideia das múltiplas modernidades presume que o melhor caminho para entender o mundo contemporâneo - inclusive para explicar a história da modernidade - é vê-la como uma história de contínua constituição e reconstituição de uma multiplicidade de programas culturais". ${ }^{171}$ De fato, sendo difícil verificar quais aspectos são continuidades "pré-modernas" e quais foram re-elaborados como "modernos", a teoria atual tende a considerar a existência mais de modernidade(s) do que de pré-modernidade(s) mesmo em manifestações culturais tradicionais. Diferenças de organização dos âmbitos de comunicação, o conteúdo de suas comunicações e a própria distinção entre esses âmbitos são então observados em seu contraste com a modernidade hegemônica, mas já não mais enquanto resquícios do passado, e sim enquanto outras formas (im)possíveis do presente:

\footnotetext{
Id., p. 846.

167 EISENSTADT, Shmuel N. Multiple modernities. cit., p. 11.

168 Cf. WITTROCK, Björn. Modernity: one, none, or many? European origins and modernity as a global condition. In: EISENSTADT, Shmuel N. (Ed.). Multiple modernities. New Brumswick: Transaction, 2000. p. 32 .

169 EISENSTADT, Shmuel N. Multiple modernities. cit., p. 1.

170 WITTROCK, Björn. Modernity: one, none, or many? European origins and modernity as a global condition. cit., p. 32-35.

171 EISENSTADT, Shmuel N. Multiple modernities. cit., p. 2.
} 
em muitos casos, a observação é de que "[i]sto pode recordar de longe uma ordem muito antiga. Mas de fato é, hoje em dia, efeito colateral da sociedade funcionalmente diferenciada [...]". ${ }^{172}$ Assim, considera-se na análise de muitas manifestações artísticas, religiosas, econômicas desviantes do padrão dominante que "[n]ão se trata de 'survivals', senão de formações novas que buscam a oposição" ${ }^{173}$ ou que se desenvolvem em caminhos mutuamente opacos e ignorados uns pelos outros.

Pela ideia de "múltiplas modernidades" não se pode, porém, conceber uma falsa igualdade de "contribuições" de cada modernidade. A maioria do território mundial, em suas segmentações, apenas recente e restritivamente (por poucos e com restrições) é reconhecida como espaço moderno e, por mais crítica que seja a teoria, é difícil que filtre totalmente a normatividade inerente a qualquer uso que se dá a "modernidade", sempre tomada como criação ocidental - como de fato é, conquanto tenha pretensão de ser uma autodescrição do Ocidente (moderno) e seja, em seu histórico uso, de fato, uma prescrição para esses mesmos países e, principalmente, para o resto do mundo, que os haveria de tomar como mais adiantados na estrada rumo à realização da modernidade plena. Mesmo a teoria das múltiplas modernidades admite que a modernidade seria uma criação europeia pluralizada ao se descolar de sua origem e espraiar-se para múltiplos contextos culturais.

Ilustrativamente, a modernidade, com suas premissas estruturais e semânticas que formam "o núcleo comum" 174 das várias modernidades que surgiram, tem origem ocidental, ${ }^{175}$ já que a própria ideia de modernidade, em termos linguísticos, surge para designar idealmente a própria condição do Ocidente "civilizado", "culto", "positivo" (em termos simplesmente avaliativos e no sentido positivista). ${ }^{176}$

Analogamente à modernidade, a cultura nasce como plano da vida social “especifico da Europa, especifico, pois, de uma região em que houve expressamente esse

172 LUHMANN, Niklas. La sociedad de la sociedad. cit., p. 502. Bertalanffy (BERTALANFFY, Ludwig Von. Teoria geral dos sistemas. Tradução de Francisco M. Guimarães. 3. ed. Petrópolis: Vozes, 1977. p. 308-309, grifo no original) identifica o surgimento do relativismo cultural a partir da década de 1920, aproximadamente, e nota: "Parece que este desenvolvimento começou na história da arte", primeiramente com o historiador vienense Riegl, que "[i]ntroduziu o conceito de Kunstwollen, termo que pode ser traduzido por 'intenção artística'. O caráter não naturalista da arte primitiva foi concebido como sendo consequência não da falta de habilidade ou de conhecimento mas antes como expressão de uma intenção artística diferente da nossa, não interessada na reprodução realista da natureza. [...] Esta concepção foi mais tarde desenvolvida por Worringer, que demonstrou pelo exemplo da arte gótica que os modos artísticos diametralmente opostos aos cânones clássicos resultam não da impotência técnica mas de uma diferente concepção do mundo. Não é que os escultores e pintores góticos não soubessem como representar corretamente a natureza, mas o que acontecia é que sua intenção era diferente, não visava à arte representativa".

173 LUHMANN, Niklas. La sociedad de la sociedad. cit., p. 631.

174 EISENSTADT, Shmuel N. Multiple modernities. cit., p. 3.

175 Id., p. 7.

176 WITTROCK, Björn. Modernity: one, none, or many? European origins and modernity as a global condition. cit., p. 36: "Talvez as teorias da modernidade não passem de uma ideologia do final da ciência social do século dezenove". 
interesse [comparatístico] e onde se estabeleceram os pontos de comparação", havendo como consequência de uma europeização do ocidente o fato de se designar artes e culturas até mesmo onde "nem os criadores nem os contempladores sabiam" que tais manifestações existiam. O conceito de cultura, uma vez descentrado da Europa iluminista e submetido a uma universalização - com a ideia de que todos têm cultura - ganhou crescente ambivalência e definições contraditórias. ${ }^{177} \mathrm{O}$ mesmo ocorreu com a noção de modernidade. ${ }^{178}$

Demandas como aquela por uma tolerância multicultural "atestam o contínuo desenvolvimento das modernidades múltiplas, ou das múltiplas interpretações da modernidade - e, sobretudo, das tentativas de 'desocidentalização', privando o Ocidente de seu monopólio sobre a modernidade". ${ }^{179}$

Terminologicamente, a ideia de modernidade múltiplas seria mais pluralista do que a de "várias vias de acesso à modernidade", ${ }^{180}$ que pressupõe umaúnica modernidade. No entanto, as ideias têm ampla correspondência e a diferença terminológica parece ilustrar a dificuldade de uma descrição que, sem desprezar assimetrias, não despreze os que estão em pior posição e que, sem ser simplista, consiga realizar comparações, sem tomar como "típico", como "peculiaridade cultural" algo que é extremamente nocivo dentro da própria cultura considerada. ${ }^{181}$ A alocação da valorização e do desprezo é problemática tanto nas semânticas nacionais quanto nas descrições globais, e são sempre problemáticas as distinções que os observadores adotam e as segmentações que elegem

177 LUHMANN, Niklas. La sociedad de la sociedad. cit., p. 699.

178 EISENSTADT, Shmuel N. Multiple modernities. cit., p. 14: "A variabilidade de modernidades foi obtida sobretudo pelo imperialismo e colonialismo militar e econômico, logrado por tecnologias econômicas, militares e comunicacionais superiores. A modernidade primeiro moveu-se além do Ocidente em direção a diferentes sociedades asiáticas - Japão, Índia, Burma, Sri Lanka, China, Vietnã, Laos, Camboja, Malásia, Indonésia -, aos países do meio Leste, chegando finalmente à África. No final do século vinte, encompassou quase o mundo todo, a primeira verdadeira onda de globalização".

179 Id., p. 24.

180 VILLAS BÔAS FILHO, Orlando. Teoria dos sistemas e o direito brasileiro. São Paulo: Saraiva, 2009. esp. p. 266-294.

181 Assim, tomando a corrupção, talvez exageradamente, como particularidade brasileira, Luhmann (LUHMANN, Niklas. La sociedad de la sociedad. cit., p. 639) parece chegar a uma descrição que a constata, de forma neutra, como peculiaridade cultural: "Ao dirigir a vista a determinadas regiões, fazem-se notórias certas estruturas que não se enquadram no modelo funcional destes grandes sistemas diferenciados. [...] A separação taxativa entre questões jurídicas e políticas não é usual em muitos Estados do sistema mundial e pouco serve, então, taxar de 'corruptas' as soluções aos problemas que ali se praticam. As estratégias de repartição das vantagens, de asseguramento do futuro, do tráfico de influências muitas vezes se orientam por redes de 'recomendações' pessoais - diretas ou mediatas; e isso mesmo onde as relações de clientelismo condicionadas por uma situação agrária foram derrubadas e, em seu lugar, vinculam-se a posições em organizações". Cf. Sobre corrupção e legitimação no Brasil, cf. IZAIAS, Rafael Silva. A legitimação do Estado democrático de Direito na modernidade periférica: uma observação a partir do caso brasileiro. 2010. Dissertação (Mestrado em Direito) - Faculdade de Direito, Universidade de São Paulo, São Paulo, esp. p. 114-117. 
para suas observações e descrições - tomando muitas vezes como geral o que é específico (de um país, de uma região interna ao país, de uma classe) e como específico o que é geral, elegendo-se um parâmetro (por exemplo, espacial: quer-se analisar um país) e desconsiderando-se outros (como diferenças de classe, ou entre excluídos e incluídos em determinado(s) sistema(s) ou em todos, genericamente, em certo espaço).

Não se pode deixar de notar que, mesmo dentro do enfoque teórico das múltiplas modernidades, ainda se tende a supervalorizar as fórmulas "iluminadas" dos primeiros países (auto)considerados modernos - ou dificilmente é possível diferenciar o que é prescrição (atual) do que é descrição (da semântica histórica) e identificar onde "a modernidade" foi realizada, em que medida foi realizada e em que medida é simplesmente tida como realizada, ou mesmo se se é considerado moderno simplesmente por se desejar ser moderno: “As notas promissoras, formuladas, promulgadas e até parcialmente implementadas, mesmo por curtos períodos de tempo, na virada do século dezoito, vieram a ter relevância global. A modernidade, nesse sentido, não é tanto uma nova civilização unificada, global em sua extensão, sem paralelo em sua capacidade de intrusão e destruição. Antes, modernidade é um conjunto de notas promissoras, i.e., um conjunto de esperanças e expectativas [...]". ${ }^{182}$

Decerto, é correto chegar-se ao paradoxo de que mesmo os movimentos antimodernos - nacionalistas, fundamentalistas, tradicionalistas - são modernos, pois reagem à modernidade (ou a um "projeto" específico de modernidade, entre outros possíveis) e lhe tomam algumas de suas formas semânticas e estruturais. Mesmo com tal assunção, porém, parece sempre difícil um uso conceitual normativamente neutro de "modernidade": em geral, concede-se no máximo que certo país, ideologia ou forma de organização é moderno porque é uma reação à modernidade - então, volta-se a um conceito etnocêntrico, com certas estruturas e semânticas limitadas a um determinado espaço e a um determinado período. Essas reações à "modernidade verdadeira" são modernas, mas contrapõem-se à modernidade "mainstream", constituindo uma "desviação" - então, há um padrão normativo do qual se julgar. ${ }^{183}$

Problemas semelhantes apresentam-se quanto se considera termos como subdesenvolvido, em desenvolvimento, modernidade tardia, "modernidade incompleta"184 e afins: ora são adotados no sentido crítico, jocoso, ora são assumidos como prescrições,

\footnotetext{
182 WITTROCK, Björn. Modernity: one, none, or many? European origins and modernity as a global condition. cit., p. 49, 55.

183 Esse parece ser o diagnóstico de Arnason (ARNASON, Johann P. Communism and modernity. In: EISENSTADT, Shmuel N. (Ed.). Multiple modernities. New Brumswick: Transaction, 2000, esp. p. 61) quanto ao comunismo como "uma versão de modernidade distintiva, mas no limite autodestrutiva".

184 ORTIZ, Renato. From incomplete modernity to world modernity. In: EISENSTADT, Shmuel N. (Ed.). Multiple modernities. New Brumswick: Transaction, 2000.
} 
mas sempre fica obscura e implícita a opção do Autor. Em um sentido crítico, costumase apontar a noção de "ideias fora do lugar", copiadas dos países do centro pelos da periferia do mundo. Se se tomar em consideração as críticas ${ }^{185} \mathrm{e}$ as reiterações ${ }^{186}$ à análise de Roberto Schwarz, ${ }^{187}$ chega-se ao tortuoso entendimento de que as ideologias e lugares comuns normativos tomados como "ideias fora do lugar" são, em geral, sempre fora do lugar, pois são ideologias - no sentido crítico - mesmo em seus locais de origem, onde nascem para encobrir a realidade, trazendo distorções inclusive não intencionais, pela realidade diferente vivenciada pelos produtores e pelos destinatários da ideologia estando aqui admitida uma diferença de classe. Porém, como "ideias fora do lugar", são mais fora do lugar em alguns lugares do que em outros, como ideologias importadas - está aqui implícita uma diferenciação centro/periferia entre exportador e importador.

Em sua teoria das "múltiplas modernidades", Eisenstadt ${ }^{188}$ nota que a própria diferenciação estrutural/funcional das diversas esferas da sociedade seguiu caminhos diversos, ora divergentes, ora convergentes, nas diversas sociedades - ou melhor, nas diversas porções da sociedade mundial -, que construíram assim seu próprio processo de modernização, não dissociadas uma das outras, mas também não de forma totalmente reativa - elementos endógenos e exógenos, muitos dos quais entendidos como "culturais", reagiram entre si, dando origem a múltiplas fórmulas e formas de modernidade, que não se resumiram ao esquema europeu-ocidental ou estadunidense de modernidade, mas antes tomaram a modernidade ocidental como eixo ambivalente, em relação ao qual produziram distanciamentos e aproximações, misturando tradições locais enraizadas a outras deslocadas (pela guerra, pela perseguição, pelo tráfico de escravos) e produzindo uma "contínua seleção, reinterpretação e reformulação"189 de ideias já incorporadas à semântica local ou ainda com sua origem estrangeira à vista.

Se a ideia de "múltiplas modernidades" de Eisenstadt não evita totalmente a valorização de alguns países, povos, culturas em relação a outros, a ideia de "cidadania multicultural” de Boaventura de Sousa Santos ${ }^{190}$ baseia-se em uma compreensão pela qual se tomam os ideais iluministas (emancipação, igualdade, liberdade), mas se reforça

\footnotetext{
185 VILLAS BÔAS FILHO, Orlando. Teoria dos sistemas e o direito brasileiro. cit., p. 187-204.

186 Entre outros: ORTIZ, Renato. From incomplete modernity to world modernity. cit., p. 254.

187 SCHWARZ, Roberto. As ideias fora do lugar. In: Cultura e politica. 3. ed. São Paulo: Paz e Terra. 2009.

188 EISENSTADT, Shmuel N. Multiple modernities. cit., p. 1-2.

189 Id., p. 15.

190 Cf. SANTOS, Boaventura de Sousa. Por uma concepção multicultural de direitos humanos. cit.; Towards a multicultural conception of human rights. cit.; ; NUNES, João Arriscado. Introdução: para ampliar o cânone do reconhecimento, da diferença e da igualdade. In: SANTOS, Boaventura de Sousa (Org.). Reconhecer para libertar: os caminhos do cosmopolitismo multicultural. Rio de Janeiro: Civilização Brasileira, 2003.
} 
demasiadamente o caráter eurocêntrico de outros conceitos. De certa forma, nesse discurso pós-moderno, "[o]s conceitos para a racionalidade econômica, científica ou para a razão autocrítica se voltam explicitamente contra as ataduras da tradição - sem dar-se conta de que dessa maneira eles mesmos fundam uma tradição". ${ }^{191}$ Destacadas essas necessárias ponderações, e reconhecida a dificuldade (ou a impossibilidade) de se "descentrar" satisfatoriamente as análises sociológicas, esse intento não pode ser abandonado como horizonte, como não se deve desprezar as relevantes contribuições e inovações das teorias apresentadas.

\section{O diálogo intercultural e a hermenêutica diatópica}

A manutenção não apenas das esferas individuais de liberdade, mas da liberdade nos diversos âmbitos comunicativos implica a necessidade de os direitos fundamentais culturais tutelarem a cultura em seu sentido de produção coletiva de discursos, como instituição social diferenciada em uma sociedade funcionalmente diferenciada. ${ }^{192}$

Boaventura de Sousa Santos ${ }^{193}$ propõe a construção de "diálogos interculturais ${ }^{194}$ sobre preocupações isomórficas, isto é, sobre preocupações convergentes ainda que expressas em linguagens distintas e a partir de universos culturais diferentes. Tais diálogos podem se dar no nível das interações e, principalmente, das organizações, para utilizar a distinção luhmanniana.

Nas organizações, com abertura a uma esfera pública pluralista e por meio de um consenso procedimental em que se alicercem dissensos conteudísticos, ${ }^{195}$ pode-se melhor estruturar a autoirritação da própria cultura (arte, educação, ciência, comunicação de massa sistemas relacionais e organizados constitutivos de identidades), inclusive em suas segmentações internas, bem como a irritação dos demais sistemas funcionais, como a economia e o direito, pressionando-os para a inserção de certos entendimentos sobre o tratamento da alteridade cultural em práticas comerciais e textos normativos jurídicos, por exemplo. Aumenta-se assim a complexidade de cada sistema funcional - e da sociedade

191 LUHMANN, Niklas. La sociedad de la sociedad. cit., p. 762.

192 Cf. GRABER, Christoph Beat; TEUBNER, Gunther. Art and money: constitutional rights in the private sphere? cit., p. 65.

193 SANTOS, Boaventura de Sousa. Por uma concepção multicultural de direitos humanos. cit., p. 441; . Towards a multicultural conception of human rights. cit., p. 221.

194 Sobre o tópos do diálogo inter ou transcultural (cross-cultural dialogue), cf. ZENE, Cosimo. The ethics of cross-cultural dialogue. In: SHIGEMI, Inaga; RICHARD, Kenneth L (Eds.). Crossing cultural borders: toward an ethics of intercultural communication: beyond reciprocal anthropology. Kyoto: International Reseacrh Center for Japanese Studies, 2001.

195 NEVES, Marcelo. Entre Têmis e Leviatã: uma relação difícil: o Estado Democrático de Direito a partir e além de Luhmann e Habermas. cit., p. 136-156. 
-, ampliando-se as possibilidades de comunicação em cada sistema (o que pressiona à seleção) e admitindo-se mais alternativas comunicacionais atualizáveis: mais formas de organização da atividade econômica, ${ }^{196}$ mais concepções artísticas, mais caminhos pedagógicos, etc.. ${ }^{197}$ As modernidades, então, multiplicam-se.

A "hermenêutica diatópica" parece ser o ponto fulcral para o respeito e a promoção dos direitos humanos fundamentais culturais. Pela teoria luhmanniana, entendese que, pertencentes aos sistemas funcionais da arte, da educação, da comunicação de massa e da ciência e a sistemas de interação e de organização, as comunicações no seu interior são encadeadas recursivamente e há um fechamento autopoético que as divide e as torna opacas umas às outras. Porém, as referências culturais, carregadas em boa parte da linguagem, precisam compor memória de cada sistema, para guiar a formação de sua rede de operações comunicativas. Por isso, por exemplo, a comunicação sobre uma visão de arte ancorada em certos pressupostos compartilhados pelas pessoas de concentradas em dada comunidade, situada espacialmente ou-não, precisa poder se conectar a comunicações sobre a visão de arte peculiar a outra comunidade, delimitada casuisticamente pelas pessoas que compartilham o entendimento dessa semântica. Toda semântica é localizada: algumas se expandem mais e outras menos, conforme as diferentes comunicabilidades das pessoas e organizações que as portam - certas concepções se multilocalizam, tornandose globais, por estarem associadas a outros sistemas, como a economia e os meios de comunicação, por meio de organizações e/ou acoplamentos funcionais.

Do ponto de vista jurídico, o direito à cultura deve espraiar-se em sua eficácia para incentivar ou exigir que nos diversos âmbitos da sociedade (sistemas funcionais, interações e organizações) sejam respeitadas as referências culturais localizadas (em um local restritivamente delimitado, como a região de um país, ou no mundo todo, enquanto difundidas essas referências, com maior ou menor descontinuidade, entre os vários espaços, profissões, classes, etc.).

196 No contexto do debate sobre as "múltiplas modernidades", Wittrock (WITTROCK, Björn. Modernity: one, none, or many? European origins and modernity as a global condition. cit., p. 33) exemplifica: "a maioria dos países europeus concedeu um papel muito mais proeminente ao Estado em supervisionar e mesmo formatar interações no mercado do que a América do Norte".

197 SANTOS, Boaventura de Sousa. Por uma concepção multicultural de direitos humanos. cit., p. 444; Towards a multicultural conception of human rights. cit., p. 222), afirma: "A hermenêutica diatópica baseia-se na ideia de que os topoi de uma dada cultura, por mais fortes [comunicáveis] que sejam, são tão incompletos quanto a própria cultura a que pertencem. Tal incompletude não é visível a partir do interior dessa cultura, uma vez que a aspiração à totalidade induz a que se tome a parte pelo todo. O objetivo da hermenêutica diatópica não é, porém, atingir a completude - um objetivo inatingível - mas, pelo contrário, ampliar ao máximo a consciência da incompletude mútua por intermédio de um diálogo que se desenrola, por assim dizer, com um é em uma cultura e outro em outra. Nisto reside o seu caráter diatópico". 
Além da superação do debate sobre relativismo cultural, ${ }^{198}$ destacam-se outras três fecundas premissas que Santos ${ }^{199}$ propõe para o estabelecimento de um diálogo cultural que estabeleça "uma concepção mestiça de direitos humanos” e gere a organização de "constelações de sentidos locais, mutuamente inteligíveis", que se constituam "em rede de referências normativas capacitantes": 1) "todas as culturas possuem concepções de dignidade humana, mas nem todas elas a concebem em termos de direitos humanos"; 2) "todas as culturas são incompletas e problemáticas nas suas concepções de dignidade humana" e em sua semântica como um todo; 3) as culturas apresentam diferentes "círculos de reciprocidade" em suas concepções de dignidade humana, direitos humanos fundamentais e demais entendimentos temporal e espacialmente difundidos e consolidados; deve-se preferir as concepções que, a cada caso, apresentem um maior "círculo de reciprocidade": não-só maior coincidência com as concepções equivalentes das demais culturas, mas também maior propensão ao diálogo com estas e maior capacidade de absorver-lhes as diferenças e nuances.

Esses pressupostos são a base da fecunda ideia de Boaventura de Sousa Santos ${ }^{200}$ cunhada de "hermenêutica diatópica". Há lugares comuns (topoi) que caracterizam cada comunidade cultural especificamente, segundo autodescrição reconhecida pelas demais comunidades. Esses lugares comuns são palavras ou expressões - condensações de ideias, portanto - que se acoplam às comunicações, aumentando sua chance de entendimento dentro de cada comunidade que partilhe tais signos linguísticos (ou artísticos). Os topoi atuam no plano da segmentação espacial dos sistemas funcionais e da sociedade mundial (distinguindo-se nacionalidades, por exemplo), ou presidem a diferenciação por outros critérios (classe, gênero, etc.) dos sistemas sociais. Essas segmentações estão construídas conforme a difusão dos signos - ou melhor, de seus significados respectivos - utilizados predominantemente em dada área do planeta e/ou compartilhados dentre certo conjunto de pessoas. Tais significados são adotados nas comunicações de cada sistema funcional (educação, ciência, direito, economia), em esferas não diferenciadas sistemicamente (como a moral) - reproduzidas, essas esferas e sistemas, em termos mundiais -, e nos sistemas de interação e organizações que atuam em determinada área. Equivalem aos códigos-diferença dos sistemas funcionais (ter/não ter, lícito/ilícito), que na verdade são topoi generalizados na sociedade mundial, de alta

198 Luhmann (LUHMANN, Niklas. La sociedad de la sociedad. cit., p. 856-857) critica como interpretações "da moda", como "pluralismo dos jogos linguísticos de Wittgenstein, a tese do relativismo cultural ou a pluralidade de discursos do assim chamado "pós-modernismo"”.

199 SANTOS, Boaventura de Sousa. Por uma concepção multicultural de direitos humanos. cit., p. 441-443; Towards a multicultural conception of human rights. cit., p. 220-222.

200 SANTOS, Boaventura de Sousa. Por uma concepção multicultural de direitos humanos. cit., p. 443-451; . Towards a multicultural conception of human rights. cit., p. 222-227. 
comunicabilidade nos respectivos sistemas funcionais, difundidos praticamente por todos os espaços e para todas as pessoas do mundo. As comunidades são, pois, conjuntos de pessoas, concentradas em dada região ou não, que compartilham do sentido de dado(s) topos ou topoi (note-se que compartilhar um sentido implica inteligibilidade, mas não necessariamente dissenso ou consenso substancial).

Alguns topoi têm uso praticamente restrito a certa comunidade de dimensões não globais, não sendo compartilhados por (quase) todas as pessoas (incluídas) do planeta. Dentre esses topoi, os mais relevantes precisam ser esclarecidos também a pessoas de fora dessa comunidade - talvez se incorporando com relevância em suas comunicações e tornando-se, portanto, topoi de comunidades mais amplas (no limite, mundiais).

Por uma hermenêutica diatópica reforçam-se os intercâmbios de referências culturais e ameniza-se a tendência natural a que topoi fortes em uma cultura tornem-se “altamente vulneráveis e problemáticos quando 'usados' em uma cultura diferente”, sendo, no melhor dos casos, "rebaixados de premissas de argumentação a meros argumentos". ${ }^{201}$

A formação da diferença na sociedade está na própria conformação do meio do sentido pela linguagem, que permite a formação de nomes e qualificações de fácil reprodução pelos sistemas, os quais podem ser aplicados em "situações distintas e imprevisíveis". Historicamente, esses topoi tomam a forma de "uma designação rígida e invariante", que logicamente pressupõe o seu contrário, o que dá origem a distinções como "gregos/bárbaros, cristãos/pagãos ou, em um sentido mais moderno - ainda que renunciando a nomes próprios: civilizado/selvagem". ${ }^{202}$

O esclarecimento dos topoi de uma comunidade aos membros externos a esta implica a necessidade de uma abertura ao diálogo e ao entendimento, cumprindo-se as premissas apontadas por Boaventura Santos. O alargamento dos espaços e pessoas nos quais ou pelas quais certa ideia é entendida implica maior comunicabilidade desta ideia e maior propensão de influência (autoirritação dos âmbitos, sistêmicos ou não, em que são utilizadas e irritação das demais esferas em seu ambiente). Facilita também o acoplamento operacional de comunicações que veiculem esta ideia a outras comunicações, enriquecendo a autopoiese e complexificando o respectivo âmbito comunicacional, sistêmico ounão - e, logicamente, complexificando a sociedade e aumentando as alternativas, o que provoca um reforço da pressão por seleções. Nesse sentido, (1) esclarecer os topoi de uma comunidade para pessoas a ela externas - expandindo seu uso potencial - e (2) possibilitar o enriquecimento de sentido ou a (re)construção de outros topoi, na comunidade que

\footnotetext{
201 SANTOS, Boaventura de Sousa. Por uma concepção multicultural de direitos humanos. cit., p. 443; . Towards a multicultural conception of human rights. cit., p. 222.

202 LUHMANN, Niklas. La sociedad de la sociedad. cit., p. 698.
} 
desconhecia os topoi alheios, são as funções da "hermenêutica diatópica", conceito-chave para uma concepção multi ou transcultural de direitos humanos.

Por esse processo, os topoi retomam um de seus usos históricos, que foi o de "servir à discussão dos problemas". ${ }^{203}$ Problemas equivalentes enfrentados pelas diversas comunidades podem encontrar soluções equivalentes, já que cada cultura, ao consagrar alguns conceitos como lugares comuns típicos e específicos de suas comunicações, trabalha com algumas distinções e ignora outras. $\mathrm{O}$ conhecimento de outras distinções, pelo contato intercultural, desloca a observação, afastando alguns pontos cegos e trazendo outros, de modo que na justaposição das distinções e pontos cegos não se atinge a completude, mas decerto enriquece-se a comunicação e chega-se a um maior entendimento dos pontos de vista de uma e de outra parte, o que é pré-condição para consensos e dissensos. Nesse sentido, "a hermenêutica diatópica tem de centrar-se não nos 'mesmos' temas, mas nas preocupações isomórficas [...]". ${ }^{204}$

Assim, “[...] deve-se distinguir agora entre valores válidos sem exceção e programas com validade condicional - isto tão só porque os sistemas funcionais particulares identificam de distintas maneiras seus códigos invariáveis e seus programas variáveis". ${ }^{205}$ No plano da cultura, as múltiplas culturas podem partilhar uma base de programas de validade incondicional, mas é certo que cada cultura produz e reproduz alguns programas, com base nos quais atua, que são observados, do ponto de vista do âmbito mundial da cultura, como programas de validade condicional. Ilustrativamente, as diferentes concepções de direitos humanos podem obedecer a diferenças culturais (nacionais ou da dicotomia civilizacional Ocidente/Oriente), econômicas (pobres/ricos, países do Norte ou do Sul) e ideológicas (socialismo, socialdemocracia, liberalismo, etc.).

A teoria sistêmica luhmanniana reconhece tanto o conceito de topoi quanto o de isomorfismo, não sendo descabido o diálogo entre as concepções de Luhmann e Boaventura Santos, no que concerne a tais construções conceituais. Para Luhmann, ${ }^{206}$ “os topoi guiam a motivação, dirigindo-a a generalizações” nas dimensões objetual (desenhando fronteiras entre sistemas e seus ambientes), temporal (donde nascem as diferenciações temporais, antes/depois, passado/futuro) e social (no exercício da alteridade entre pessoas mutuamente opacas umas às outras e que, pelo seu fechamento autopoiético - em seus respectivos sistemas psíquicos -, precisam colocar-se em comunicação, ego e alter).

\footnotetext{
203 VIEHWEG, Theodor. Tópica e jurisprudência: uma contribuição à investigação dos fundamentos jurídicocientíficos. Tradução de Kelly Susane Alflen da Silva. Porto Alegre: Fabris, 2008. p. 39.

204 SANTOS, Boaventura de Sousa. Por uma concepção multicultural de direitos humanos. cit., p. 457.

205 LUHMANN, Niklas. La sociedad de la sociedad. cit., p. 611.

206 Id., p. 251.
} 
Por outro lado, o conceito de isomorfismo, adotado por Santos, é elaborado tanto pela clássica teoria dos sistemas (abertos) - estando presente em Bertalanffy ${ }^{207}$ quanto pela teoria dos sistemas sociais autopoiéticos de Luhmann, ${ }^{208}$ que chega a adotar também, em sua sociologia do direito, o conceito de "equifinalidade" de Bertalanffy, esclarecendo que "[p]or equifinalidade é entendido o fato de que o mesmo estado de um sistema (aqui: o direito) pode ser atingindo a partir de diferentes constelações originais e através de diferentes caminhos". 209

Como nota Bertalanffy, há possibilidades de variações dentro mesmo do sistema científico, por exemplo, proporcionadas pelo fato de este sistema desenvolver-se mundialmente e, com isso, cobrir loci com diferentes pressupostos culturais. ${ }^{210}$ Portanto, no plano de cada sistema social funcional (economia, educação, etc.), o diálogo diatópico, entre conceitos/distinções utilizados dentro de uma ou outra cultura, pressupondo ou encontrando enfim a incompletude de cada cultura, ${ }^{211}$ permite enriquecer as observações e descrições dos sistemas e pelos sistemas, elidindo discursos de conjunção de valores (ideologias) que se fazem coerentes por grandes vazios não revelados em seu percurso lógico de pressupostos.

No plano da cultura, enquanto sistemas funcionais artístico, educacional, científico, religioso e dos meios de comunicação de massa e sistemas organizacionais e de interação também não diretamente submetidos a esses sistemas funcionais, a comunicação diatópica tem referência ainda mais direta e imediata, propagando seus efeitos tanto mais quanto mais irritar o sistema dos meios de comunicação de massa.

207 BERTALANFFY, Ludwig Von. Teoria geral dos sistemas. cit., esp. p. 114-122; An outline of general system theory. The British Journal for the Philosophy of Science, London, v. 1, n. 2, p. 134-165, 1950, esp. p. 136-139.

208 LUHMANN, Niklas. Theories of distinction: redescribing the descriptions of modernity. Tradução de Joseph O’Neil, Elliott Schreiber, Kerstin Behnke e William Whobrey. Stanford: Stanford University, 2002. p. 49.

209 LUHMANN, Niklas. Sociologia do direito I. cit., p. 241.

210 Bertalanffy (BERTALANFFY, Ludwig Von. Teoria geral dos sistemas. cit., p. 310): “Assim, as categorias da criação artística parecem depender, em cada caso, da cultura. É bem sabido que Spengler estendeu esta tese até incluir as categorias cognoscitivas. Segundo seu modo de ver, o chamado a priori contém, ao lado de um pequeno número de formas de pensamento universalmente humanas e logicamente necessárias, também formas de pensamento que são universais e necessárias não para a humanidade em totalidade mas só para a particular civilização em questão. Assim, há vários e diferentes 'estilos de conhecimento', característicos de certos grupos de seres humanos. [...] As categorias linguísticas e culturais em geral não alterarão as potencialidades da experiência sensível. Modificarão porém a percepção, isto é, determinarão que os aspectos da realidade experimentada serão focalizados e acentuados e quais os que serão subestimados. [...] Uma das importantes tendências do desenvolvimento da ciência é que novos aspectos, anteriormente despercebidos, serão 'vistos', isto é, caem no foco da atenção e da percepção. Inversamente, um importante obstáculo é que os óculos de uma certa concepção teórica não deixam compreender fenômenos que, em si mesmos, são perfeitamente evidentes".

211 SANTOS, Boaventura de Sousa. Por uma concepção multicultural de direitos humanos. cit., p. 444; . Towards a multicultural conception of human rights. cit., p. 222. 
É também a "hermenêutica diatópica" uma proposta de grande relevância para a concretização dos direitos culturais na medida em que permita a difusão de ideias típicas de várias culturas (comunidades culturais), reforçando aquelas com menor comunicabilidade, menos presentes nas memórias historicamente formadas dos âmbitos comunicativos da sociedade mundial. Tal procedimento tem efeitos no desenvolvimento de pré-condições (fundamentalmente, o entendimento de concepções culturais desconhecidas por pessoas e organizações) para o tratamento isonômico das diversidades culturais, inclusive na esfera das interações pessoais e tanto nos espaços "privados" quanto nos "públicos". Isso porque a "hermenêutica diatópica" há que se desenvolver por meio dos procedimentos da esfera pública, mas deve chegar ao mundo da vida, às interações, às organizações e aos sistemas funcionais.

Além da esfera pública política, como indutora inicial do diálogo intercultural, cabe notar a importância das interações e organizações diversas enquanto promotores da "hermenêutica diatópica". A formação de qualquer sistema social autopoiético tem como ponto de partida a percepção da dupla contingência inerente à comunicação; tornada consciente a opacidade mútua de um interlocutor com relação ao outro, desenha-se a distinção sistema/ambiente. Assim é que podem constituirse "pequenos sistemas que continuamente se formam e tornam a desfazer-se", ${ }^{212} \mathrm{sem}$ necessitar de referência aos grandes e estáveis sistemas funcionais da sociedade, nem à sociedade mesma, embora estejam em seu interior - sociedade e interação constituem um mesmo "continuum de realidade da comunicação societal". ${ }^{213}$ As interações são esses sistemas fugazes que podem manifestar-se desde os encontros mais minúsculos de tipo pessoal ou impessoal, nos quais - "contanto que tenha lugar comunicação - realizam a sociedade". ${ }^{214}$ Obviamente, a diferenciação dos sistemas de interação (intermitentes) em relação ao sistema social mais amplo - a sociedade (mundial) - varia historicamente. ${ }^{215}$

As interações, ao delimitarem-se como lado interno de uma distinção própria entre sistema e entorno, produzem-se a si mesmas (são sistemas autopoiéticos) e traçam sua própria história, podendo reduzir sua complexidade sistêmica ao desenvolverem certo grau de indiferença com relação à sociedade mesma, esta na condição de seu ambiente sistêmico. ${ }^{216}$ Apesar de não operar na base da comunicabilidade de todas as percepções dos interlocutores - apenas tornando expressáveis uma parcela ínfima -, as interações produzem excedentes de informação que criam múltiplas possibilidades para uma referência posterior que, continuando a comunicação, seja enlaçada na rede

212 LUHMANN, Niklas. La sociedad de la sociedad. cit., p. 644.

213 Id., p. 647. (grifo no original).

214 Id., p. 645.

215 Id., p. 474.

216 Id., p. 646, 654. 
recursiva que vem se formando. ${ }^{217}$ Nota-se que, embora a sociedade não possa ser ordenada teleologicamente, as interações podem ser dirigidas finalisticamente. ${ }^{218}$ Daí poderem servir à finalidade da construção do entendimento mútuo, gerador de dissenso ou consenso, a partir do esclarecimento intercultural dos respectivos conceitos culturalmente dependentes.

Nesse sentido, também organizações presentes nos diversos sistemas funcionais (economia, educação, etc.) podem promover o mútuo intercâmbio de conhecimentos e discursos pertinentes em seu âmbito (é o caso de congressos e periódicos internacionais no sistema científico). $\mathrm{O}$ fomento a tais práticas internacionais que levam ao diálogo intercultural é relevante política pública, mas também cabe a outras organizações - empresas, universidades privadas, etc. - a responsabilidade na efetivação do direito à cultura, a partir do momento em que se lhes conceba a eficácia para as relações entre particulares.

As medidas de internacionalização visando ao diálogo intercultural podem, portanto, incluir-se como promoção dos diversos direitos (humanos e fundamentais) culturais que, na esteira de Chaui, ${ }^{219}$ poder-se-ia identificar como: o "direito à informação" sobre a cultura, o que inclui especialmente os serviços dos sistemas funcionais da educação, da ciência e da comunicação de massa; o "direito à fruição cultural", que está ligado à oportunidade de assistir a eventos culturais e consumir bens e serviços culturais; o “direito à produção cultural”, isto é, a tomar parte da produção de cultura enquanto artista (profissional ou amador), vinculado tanto à liberdade de expressão quanto à necessidade de fomento às atividades artísticas; o "direito à participação" na gestão das organizações da área cultural, na definição das políticas públicas de implementação do direito à cultura, etc.

No âmbito da cultura é que tomam seu lugar próprio as referências identitárias, notadamente por referências - implícitas ou explícitas, nas diversas comunicações dos mais variados sistemas, uns irritando aos outros - a papéis desempenhados nos diversos sistemas (aluno/professor, trabalhador braçal/administrador, fruidor de arte/artista, etc.), a diferenciações por pertencimento a países (segundo a diferenciação centro/periferia e a segmentação por Estados soberanos), por pertencimento a classes sociais, por pertencimento a certas organizações, entre outras formas de distinção pessoal. Os direitos humanos fundamentais culturais têm, como uma de suas principais operacionalidades, a fixação de exigências normativas de respeito igual a culturas desiguais, no sentido de permitir o tratamento igual de reivindicações expressas em conceitos (condensações

\footnotetext{
217 Id., p. 646.

218 Id., p. 649.

219 CHAUI, Marilena. Cidadania cultural: o direito à cultura. cit., p. 96-101.
} 
de sentido) de forte referência local (âmbito espacial ou pessoal restrito). A explicação desses conceitos e sua igual consideração na esfera pública em relação aos equivalentes predominantes em dado grupo social (país ou, no limite, o mundo) devem induzir a conformação de diálogos interculturais que permitam o enlace das comunicações referidas a esses conceitos, equilibrando conceitos de comunicabilidade desigual em dado espaço. Uma vez dadas as condições institucionais e reproduzido permanentemente este diálogo na esfera pública, os múltiplos sistemas funcionais poderão absorver os resultados das conversações (captando-os seja por meio de interações, seja por organizações) e implementar eficazmente entendimentos "mestiços", multi ou transculturais em suas respectivas operações.

A esfera pública política, liderada pelo Estado, pelo terceiro setor e por organizações supra, trans ou internacionais (podendo também ser promovida por empresas "sustentáveis"), pode travar o processo inicial de clarificação de uns conceitos em relação aos outros (na forma do confronto organizado entre demandas divergentes), e assim as comunicações enraizadas em conceitos de diferentes graus de comunicabilidade podem ganhar maior acoplabilidade operacional umas às outras, envolvendo-se em uma mesma rede autopoiética em condições menos desiguais.

Em referência direta à questão dos direitos humanos, o diálogo intercultural precisa desenvolver-se também nas relações transconstitucionais ${ }^{220}$ que se implementam nos diversos planos das relações sub, supra, inter e transnacionais, envolvendo agentes tão diversos quanto órgãos juridicionais, grandes corporações, Estados, organizações internacionais, organizações não governamentais e povos não estatalmente organizados. Nesse sentido, tratando do "transconstitucionalismo entre ordens jurídicas estatais e ordens locais extraestatais", ${ }^{221} \mathrm{Neves}^{222}$ coloca que "há um paradoxo do transconstitucionalismo, pois ele se envolve em conversas constitucionais com ordens normativas que estão à margem do próprio constitucionalismo. Mas essa situação é resultante da necessidade intrínseca ao transconstitucionalismo de não excluir o desenvolvimento de institutos alternativos que possibilitem um diálogo construtivo com essas ordens dos antropológicoculturalmente 'diferentes', baseadas milenarmente no território do respectivo Estado".

Comunicação implica criação de sentido por meio de distinções. Uma vez compreendido o sentido, pode-se ignorá-lo, bem como à operação que o criou, inexistindo então comunicação. Por outro lado, se se toma como premissa de um comportamento posterior uma compreensão anterior, houve comunicação, e o enlace das operações do sistema se produz tanto pela comunicação negativa quanto pela comunicação afirmativa

\footnotetext{
220 NEVES, Marcelo. Transconstitucionalismo. cit.

221 Id., p. 216-229.

222 Id., p. 217.
} 
da anterior. ${ }^{223}$ Daí que a comunicação que opere a "hermenêutica diatópica", ao esclarecer a pluralidade de conceitos equivalentes nas diversas culturais, possa implicar tanto dissenso quanto consenso.

De um ponto de vista jurídico, na esteira de Häberle, ${ }^{224}$ considerada a própria constituição como produto cultural (invenção histórica) e o direito constitucional como uma ciência da cultura, os vários âmbitos comunicativos da sociedade tornam-se, conscientemente ou inconscientemente, intérpretes de textos constitucionais, sendo que o fechamento de cada comunidade cultural constitucional deve combinar-se também nesse plano - de uma hermenêutica constitucional produzida consciente ou inconscientemente, também fora do direito - a uma abertura ao diálogo diatópico.

De modo mais amplo, a construção do diálogo intercultural precisa penetrar na memória dos diversos sistemas para reproduzir-se enfim estavelmente. A memória permite ao sistema utilizar os resultados de seleções prévias como base para suas presentes operações. Essas seleções são contingentes, mas não arbitrárias, já que fundadas no estado do sistema a elas contemporâneo (memória formada até então) e realizadas segundo os códigos e programas que dão especificidade a cada atribuição de sentido operada pelo sistema. Cada seleção de sentido é contingente, mas limitada apenas às virtualidades que se abrem por uma seleção anterior, que gera um excedente de remissões possíveis. O enlace das comunicações constitui a história do sistema autopoiético e a recursividade de suas próprias operações é engendrada principalmente pelas palavras (linguagem) mas também por outros objetos, que se enriqueçam semanticamente e ganhem caráter simbólico. ${ }^{225}$

A história sistêmica é produzida pela "[...] faculdade da memória [que] constrói estruturas de uso apenas momentâneo para conservar a seletividade e reduzir as possibilidades de enlace [recursivo das comunicações]. Crer na existência de identidades que perduram no tempo é uma autoilusão dos sistemas que formam sentido, identidades que sempre existiram e que sempre existirão [...]. Todo orientar-se é construção, é distinção que se reatualiza de momento a momento". ${ }^{226}$ A cultura é constituída principalmente por ideias que são reatualizadas, mas que originalmente tiveram um potencial inovativo capaz de chamar a atenção; nessa conjunção de ineditismo original e redundância constante, certos conceitos/distinções gravam-se na memória coletiva e guiam os raciocínios

223 LUHMANN, Niklas. La sociedad de la sociedad. cit., p. 262.

224 HÄBERLE, Peter. El Estado constitucional. Tradução de Héctor Fix-Fierro. Lima: Universidad Nacional Autónoma de México; Pontificia Universidad Católica del Perú, 2003, esp. p. 149-62; Libertad, igualdad, fraternidad: 1789 como historia, actualidad y futuro del Estado constitucional. Tradução de Ignacio Gutiérrez Gutiérrez. Madrid: Trotta, 1998. p. 45-65.

225 LUHMANN, Niklas. La sociedad de la sociedad. cit., p. 28-32.

226 Id., p. 28. 
posteriores: "Frases utilizam-se de muitas palavras, isto é, de muitas distinções para dizer algo determinado, mas apenas aquilo que permanece por curto ou longo tempo na memória 'faz a diferença"'. ${ }^{227} \mathrm{O}$ diálogo diatópico, portanto, é fomentador de uma pluralização do conteúdo das memórias sistêmicas e tem aí sua eficácia.

\section{Conclusão}

O diálogo inter, trans ou multicultural pode desconstruir os discursos em que se fundam as culturas, reduzindo e multiplicando seus pontos cegos; assim, reconstruindo suas diferenças e complementaridades na forma de discursos mais complexos (trans, inter ou multiculturais), bem como construindo pontes para se traduzir um conceito de um "espaço" ou grupo a outra comunidade cultural.

Paradoxalmente, o diálogo (multi, trans ou inter) cultural, garantido pela concretização e realização dos direitos humanos fundamentais culturais e por este meio promovido, é pressuposto da própria concretização jurídica e realização fática do direito humano fundamental à cultura. Seja para guiar a produção de textos jurídicos, seja para concretizá-los, enquanto normas e realizá-los no plano dos diversos sistemas sociais, o diálogo cultural coloca-se como meio da própria implementação dos direitos culturais. Por outro lado, dependem os direitos culturais da criação normativa e da implementação por este mesmo procedimento (que os pressupõe). Na perspectiva da produção e realização do direito, portanto, os direitos fundamentais culturais atuam como fator e produto do sistema jurídico, trazendo ao direito uma irritação proveniente de âmbitos comunicacionais (sistemicamente estruturados ou-não) e, também, produzindo autoirritações do próprio direito sobre si mesmo.

O Estado Democrático de Direito permanece como organização privilegiada para a produção jurídica e a realização fática dos direitos fundamentais, dentre estes os próprios direitos culturais. Mas não-só este, como também outros agentes, incluindose organizações internacionais, supranacionais e transnacionais, têm hoje potencial estruturante de uma esfera pública política que, partindo de interações e organizações, promova a "hermenêutica diatópica"228 como procedimento para o diálogo inter, trans ou multicultural.

São Paulo, abril de 2014.

227 LUHMANN, Niklas. A realidade dos meios de comunicação. cit., p. 42.

228 SANTOS, Boaventura de Sousa. Por uma concepção multicultural de direitos humanos. cit.; Towards a multicultural conception of human rights. cit. 


\section{Referências}

ADORNO, Theodor W; HORKHEIMER, Max. Dialética do esclarecimento: fragmentos filosóficos. Tradução de Guido Antonio de Almeida. Rio de Janeiro: Zahar, 1985.

AÑON, María José. El reconocimiento de los derechos culturales de las minorías en Europa. In: INSTITUTO E DERECHOS HUMANOS "BARTOLOMÉ DE LAS CASAS" - UNIVERSIDAD CARLOS III DE MADRID; FUNDACIÓN EL MONTE. El derecho en red: estudios en homenaje al profesor Mario G. Losano. Madrid: Dykinson, 2006. p. 39-67.

ARENDT, Hannah. Entre o passado e o futuro. Tradução de Mauro W. Barbosa. 6. ed. São Paulo: Perspectiva, 2009.

ARNASON, Johann P. Communism and modernity. In: EISENSTADT, Shmuel N. (Ed.). Multiple modernities. New Brumswick: Transaction, 2000. p. 61-90.

BERTALANFFY, Ludwig Von. Teoria geral dos sistemas. Tradução de Francisco M. Guimarães. 3. ed. Petrópolis: Vozes, 1977.

An outline of general system theory. The British Journal for the Philosophy of Science, London, v. 1, n. 2, p. 134-165, 1950.

BOSI, Alfredo. Colônia, culto e cultura. In: . Dialética da colonização. São Paulo: Companhia das Letras, 1992. p. 11-63.

BOURDIEU, Pierre. Questões de sociologia. Tradução de Jeni Vaitsman. Rio de Janeiro: Marco Zero, 1983.

CHAUI, Marilena. Cidadania cultural: o direito à cultura. São Paulo: Perseu Abramo, 2006.

. Cultura e democracia: o discurso competente e outras falas. 12. ed. São Paulo: Cortez, 2006.

COSTA, Sérgio. Dois Atlânticos: teoria social, anti-racismo, cosmopolitismo. Belo Horizonte: Ed. UFMG, 2006.

. ; DOMINGUES, José Maurício; KNÖBL, Wolfgang; SILVA, Josué Pereira da. How plural is modernity? Zentrum und Peripherie, München, v. 3, p. 3-9, 2006.

EAGLETON, Terry. A idéia de cultura. Tradução de Sandra Castello Branco. São Paulo: Ed. Unesp, 2005.

EISENSTADT, Shmuel N. Multiple modernities. In: . (Ed.). Multiple modernities. New Brumswick: Transaction, 2000. p. 1-29.

FISCHER-LESCANO, Andreas. A teoria crítica dos sistemas da Escola de Frankfurt. Tradução de Rúrion Melo. Novos Estudos Cebrap, São Paulo, v. 86, p. 163-177, 2010. 
FOUCAULT, Michel. Em defesa da sociedade: curso no Collège de France (1975-1976). Tradução de Maria Ermantina Galvão. São Paulo: Martins Fontes, 2002.

FREIRE, Paulo. Educação como prática da liberdade. 8. ed. Rio de Janeiro: Paz e Terra, 1978.

FRIESE, Heidrun; WAGNER, Peter. Not all that is solid melts into air: modernity and contingence. In: FEATHERSTONE, Mike; LASH, Scott (Eds.). Spaces of culture: city, nation, world. London: Sage, 1999. p. 101-115.

GRABER, Christoph Beat; TEUBNER, Gunther. Art and money: constitutional rights in the private sphere? Oxford Journal of Legal Studies, Oxford, v. 18, n. 1, 1998.

GRIMM, Dieter. Multiculturalidad y derechos fundamentales. In: GUTIÉRREZ GUTIÉRREZ, Ignacio (Ed.). Derecho constitucional para la sociedad multicultural. Madrid: Trotta, 2007. p. 5169.

HÄBERLE, Peter. El Estado constitucional. Tradução de Héctor Fix-Fierro. Lima: Universidad Nacional Autónoma de México; Pontificia Universidad Católica del Perú, 2003.

. Libertad, igualdad, fraternidad: 1789 como historia, actualidad y futuro del Estado constitucional. Tradução de Ignacio Gutiérrez Gutiérrez. Madrid: Trotta, 1998.

HABERMAS, Jürgen. O discurso filosófico da modernidade. Tradução de Luiz Sérgio Repa e Rodnei Nascimento. São Paulo: Martins Fontes, 2000.

IZAIAS, Rafael Silva. A legitimação do estado democrático de direito na modernidade periférica: uma observação a partir do caso brasileiro. 2010. Dissertação (Mestrado) - Faculdade de Direito, Universidade de São Paulo, São Paulo.

LIPOVETSKY, Gilles; SERROY, Jean. A cultura-mundo: resposta a uma sociedade desorientada. Tradução de Maria Lúcia Machado. São Paulo: Companhia das Letras, 2011.

LUHMANN, Niklas. La sociedad de la sociedad. Tradução de Javier Torres Nafarrate. México: Herder, 2007.

. El arte de la sociedad. Tradução de Javier Torres Nafarrate. México: Herder, 2005.

. A realidade dos meios de comunicação. Tradução de Ciro Marcondes Filho. São Paulo: Paulus, 2005.

. Law as a social system. Tradução de Klaus Ziegert. London: Oxford University, 2004.

. Theories of distinction: redescribing the descriptions of modernity. Tradução de Joseph

O’Neil, Elliott Schreiber, Kerstin Behnke e William Whobrey. Stanford: Stanford University, 2002.

. Sociologia do direito II. Tradução de Gustavo Bayer. Rio de Janeiro: Tempo Brasileiro, 1985.

. Sociologia do direito I. Tradução de Gustavo Bayer. Rio de Janeiro: Tempo Brasileiro, 1983. 
MARCARIAN, Eduardo S. Lugar e papel das investigações da cultura nas ciências sociais modernas. In: ENGELS, Friedrich; GEERTZ, Clifford; BAUMAN, Zygmunt; LEONTIEV, Alexei; MARCARIAN, Eduardo. O papel da cultura nas ciências sociais. Porto Alegre: Villa Martha, 1980. p. 93-114.

MOLES, Abraham A. Sociodinâmica da cultura. Tradução de Mauro W. Barbosa de Almeida. São Paulo: Perspectiva; Edusp, 1975.

MÜLLER, Friedrich. Teoria estruturante do direito I. Tradução de Peter Naumann e Eurides Avance de Souza. 2. ed. São Paulo: Revista dos Tribunais, 2009.

. Métodos de trabalho do direito constitucional. Tradução de Peter Naumann. 3. ed. Rio de Janeiro: Renovar, 2005.

Que grau de exclusão social ainda pode ser tolerado por um sistema democrático. In: PIOVESAN, Flávia (Coord.). Direitos humanos, globalização econômica e integração regional: desafios do direito constitucional internacional. São Paulo: Max Limonad, 2002. p. 567-596.

NEVES, Fabrício Monteiro. A diferenciação centro-periferia como estratégia teórica básica para observar a produção científica. Revista de Sociologia Política, Curitiba, v. 17, n. 34, 2009. p. 241 252 .

NEVES, Marcelo. Transconstitucionalismo. São Paulo: Martins Fontes, 2009.

. Entre Têmis e Leviatã: uma relação difícil: o Estado Democrático de Direito a partir e além de Luhmann e Habermas. 2. ed. São Paulo: Martins Fontes, 2008.

. A constitucionalização simbólica. São Paulo: Martins Fontes, 2007.

. The symbolic force of human rights. Philosophy \& Social Criticism, Thousand Oaks, v. 33, n. 4, 2007b. p. 411-444.

ORTIZ, Renato. From incomplete modernity to world modernity. In: EISENSTADT, Shmuel N. (Ed.). Multiple modernities. New Brumswick: Transaction, 2000. p. 249-260.

PARSONS, Talcott. Sociedades: perspectivas evolutivas e comparativas. Tradução de Dante Moreira Leite. São Paulo: Pioneira, 1969.

PIETERSE, Jan Nederveen. Globalization \& culture: global mélange. 2. ed. Lanham: Rowan \& Littlefield, 2009.

PLATÃO. Críton ou do dever. In: OS PENSADORES. Platão. São Paulo: Nova Cultural, 1999.

SANTOS, Boaventura de Sousa. Por uma concepção multicultural de direitos humanos. In:

(Org.). Reconhecer para libertar: os caminhos do cosmopolitismo multicultural. Rio de Janeiro: Civilização Brasileira, 2003. p. 427-461. 
; NUNES, João Arriscado. Introdução: para ampliar o cânone do reconhecimento, da diferença e da igualdade. In: SANTOS, Boaventura de Sousa (Org.). Reconhecer para libertar: os caminhos do cosmopolitismo multicultural. Rio de Janeiro: Civilização Brasileira, 2003. p. 25-69.

. Towards a multicultural conception of human rights. In: FEATHERSTONE, Mike; LASH, Scott (Eds.). Spaces of culture: city, nation, world. London: Sage, 1999. p. 214-229.

SARTORI, Giovanni. Pluralismo, multiculturalismo e estranei: saggio sulla società multietnica. Milano: Saggi, 2007.

SCHWARZ, Roberto. As ideias fora do lugar. In: . Cultura e política. 3. ed. São Paulo: Paz e Terra. 2009. p. 59-107.

SEN, Amartya. Desenvolvimento como liberdade. Tradução de Laura Teixeira Motta. São Paulo: Companhia das Letras, 2000.

SPOHN, Willfried. Multiple, entangled, fragmented and other modernities. Reflections on comparative sociological research on Europe, North and Latin America. Zentrum und Peripherie, München, v. 3, 2006. p. 11-22.

TAMBIAH, Stanley J. Transnational movements, diaspora, and multiple modernities. In: EISENSTADT, Shmuel N. (Ed.). Multiple modernities. New Brumswick: Transaction, 2000. p. 163-194.

TEUBNER, Gunther; FISCHER-LESCANO, Andreas. Cannibalizing epistemes: will modern law protect traditional cultural expressions? In: GRABER, Christoph; BURRI-NENOVA, Mira (Eds.). Intellectual property and traditional cultural expressions in a digital environment. Cheltenham: Edward Elgar, 2008. p. 17-45.

TÖNNIES, Ferdinand. Community and civil society. Cambridge: Cambridge University Press, 2001.

UNESCO. (Organização das Nações Unidas para Ciência, Educação e Cultura). Dez chaves para entender a Convenção para a Proteção e a Promoção da Diversidade das Expressões Culturais adotada pela $33^{a}$ Sessão da Conferência Geral da UNESCO em 2005. Brasília: UNESCO, 2007. Disponível em: <http://www.unesco.org/new/pt/brasilia/culture/international-instrumentsclt/\#c154809>. Acesso em: 15 jan. 2012.

. Os direitos culturais como direitos do homem. Porto: Telos, 1973.

UNGER, Roberto Mangabeira. Política: os textos centrais: a teoria contra o destino. São Paulo: Boitempo; Chapecó: Argos, 2001.

VIEHWEG, Theodor. Tópica e jurisprudência: uma contribuição à investigação dos fundamentos jurídico-científicos. Tradução de Kelly Susane Alflen da Silva. Porto Alegre: Fabris, 2008.

VILANOVA, Lourival. Notas para um ensaio sobre a cultura. In: . Escritos jurídicos e filosóficos. São Paulo: Axis Mundi; Ibet, 2003. p. 277-323. 
VILLAS BÔAS FILHO, Orlando. Teoria dos sistemas e o direito brasileiro. São Paulo: Saraiva, 2009.

WELSCH, Wolfgang. Transculturality: the puzzling form of cultures today. In: FEATHERSTONE, Mike; LASH, Scott (Eds.). Spaces of culture: city, nation, world. London: Sage, 1999. p. 194-213. WITTROCK, Björn. Modernity: one, none, or many? European origins and modernity as a global condition. In: EISENSTADT, Shmuel N. (Ed.). Multiple modernities. New Brumswick: Transaction, 2000. p. 31-60.

ZENE, Cosimo. The ethics of cross-cultural dialogue. In: SHIGEMI, Inaga; RICHARD, Kenneth L. (Eds.). Crossing cultural borders: toward an ethics of intercultural communication: beyond reciprocal anthropology. Kyoto: International Reseacrh Center for Japanese Studies, 2001. p. 89124.

ZOLO, Danilo. Globalização: um mapa dos problemas. Tradução de Anderson Vichinkeski Teixeira. Florianópolis: Conceito, 2010. 